Utah State University

DigitalCommons@USU

$12-2013$

\title{
Pyrolysis of Acrylonitrile-Butadiene-Styrene (ABS) Under High Heat Flux Conditions
}

James R. Wilson

Utah State University

Follow this and additional works at: https://digitalcommons.usu.edu/gradreports

Part of the Aerospace Engineering Commons

\section{Recommended Citation}

Wilson, James R., "Pyrolysis of Acrylonitrile-Butadiene-Styrene (ABS) Under High Heat Flux Conditions" (2013). All Graduate Plan B and other Reports. 346.

https://digitalcommons.usu.edu/gradreports/346

This Report is brought to you for free and open access by the Graduate Studies at DigitalCommons@USU. It has been accepted for inclusion in All Graduate Plan B and other Reports by an authorized administrator of DigitalCommons@USU. For more information, please contact digitalcommons@usu.edu.

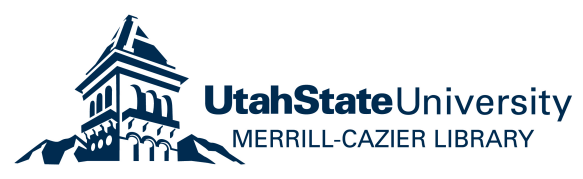




\title{
PYROLYSIS OF ACRYLONITRILE-BUTADIENE-STYRENE (ABS) UNDER HIGH HEAT FLUX CONDITIONS
}

\author{
by \\ James R. Wilson \\ A report submitted in partial fulfillment \\ of the requirements for the degree \\ of \\ MASTER OF SCIENCE \\ in \\ Aerospace Engineering
}

Approved:

Dr. Stephen A. Whitmore

Dr. David K. Geller

Major Professor

Committee Member

Dr. R. Rees Fullmer

Committee Member

\section{UTAH STATE UNIVERSITY \\ Logan, Utah}


Copyright (C) James R. Wilson 2013

All Rights Reserved 


\begin{abstract}
Pyrolysis of Acrylonitrile-Butadiene-Styrene (ABS) Under High Heat Flux Conditions

by
\end{abstract}

James R. Wilson, Master of Science

Utah State University, 2013

Major Professor: Dr. Stephen A. Whitmore

Department: Mechanical and Aerospace Engineering

Acrylonitrile-butadiene-styrene (ABS) is a common industrial plastic that is widely used for structural and piping applications. Additionally, within the past decade ABS has become the most popular material used in a type of rapid prototyping known as fused-deposition modeling (FDM). Within the past three years, ABS plastic blends have also been investigated as a potential fuel for hybrid- and solid-propelled rocket systems, exhibiting promising results. Because the use of ABS as a rocket propellant is very recent, a pyrolysis database at the heat flux levels experienced by rocket systems does not exist. Previous pyrolysis tests were performed for fire-prevention tests, at heat flux levels that were nearly an order of magnitude lower than those experienced during rocket combustion. This report investigates the properties of ABS as it is heated to temperatures over $500^{\circ} \mathrm{C}$. The resulting surface regression rates are measured and plotted against temperature to create an Arrhenius-type curve that allows important pyrolysis and kinetic combustion parameters, such as heats of gasification and activation energy, to be calculated. Accurate knowledge of these parameters is essential to high-fidelity modeling of the combustion performance of ABS as a fuel for solid and hybrid rocket systems.

(74 pages) 


\section{Public Abstract}

Pyrolysis of Acrylonitrile-Butadiene-Styrene (ABS) Under High Heat Flux Conditions

by

James R. Wilson, Master of Science

Utah State University, 2013

Major Professor: Dr. Stephen A. Whitmore

Department: Mechanical and Aerospace Engineering

Acrylonitrile-butadiene-styrene (ABS) is a common industrial plastic that is widely used for structural and piping applications. Additionally, within the past decade ABS has become the most popular material used in a type of rapid prototyping known as fuseddeposition modeling (FDM). Within the past three years, ABS plastic blends have also been investigated as a potential fuel for hybrid- and solid-propelled rocket systems, exhibiting promising results. Because the use of ABS as a rocket propellant is very recent, a pyrolysis database, describing how ABS will burn, at the temperatures and heating rates experienced by rocket systems does not exist. Previous pyrolysis tests were performed for fire-prevention tests, at heating rates that were nearly an order of magnitude lower than those experienced during rocket combustion. This report investigates the properties of ABS as it is heated to temperatures over $500^{\circ} \mathrm{C}$. The resulting surface regression rates are measured and plotted against temperature to create an Arrhenius-type curve that allows important pyrolysis and kinetic combustion parameters, such as heats of gasification and activation energy, to be calculated. Accurate knowledge of these parameters is essential to improve modeling of the combustion performance of ABS as a fuel for solid and hybrid rocket systems. 


\section{Acknowledgments}

I am grateful for everyone who has helped me get to this point in my college career. There have been countless individuals who have helped me pass classes, understand subject material, and encourage me to continue my studies. While I could write a book on all of those contributions, I would like to particularly acknowledge a few certain individuals who have made my master's degree project possible.

First, I am most grateful to Dr. Whitmore for his tireless efforts on my behalf to help me graduate. If he had not been so generous with his time and knowledge, neither my bachelor's nor my master's degrees would have been possible. His mentorship and tutelage provided the framework I needed to not only graduate, but to succeed in my future employment

I am also thankful for my professors who have taught me during my undergraduate and graduate courses. I especially thank Dr. Geller and Dr. Fullmer for their support of this project, as well as for the excellent education they gave me. I will always be appreciative of the time and effort they spent teaching me the material I will need for my future work.

Many thanks also go to Britany Chamberlain for her help in constructing the test stand used for my experiments. I wish her the best in all of her studies.

Finally, the greatest thanks goes to my wife Ashlin. Without her support, I would not have been able to finish my graduate work. Without her love, none of that work would have mattered.

James R. Wilson 


\section{Contents}

Page

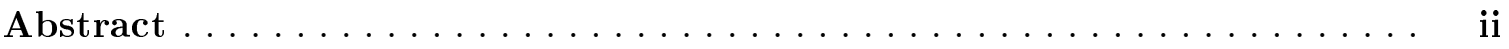

Public Abstract $\ldots \ldots \ldots \ldots \ldots \ldots \ldots \ldots \ldots \ldots \ldots \ldots \ldots \ldots$ iii

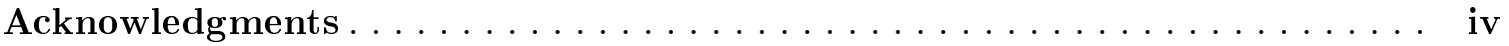

List of Figures $\ldots \ldots \ldots \ldots \ldots \ldots \ldots \ldots \ldots \ldots \ldots \ldots \ldots \ldots \ldots$

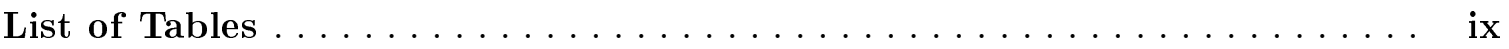

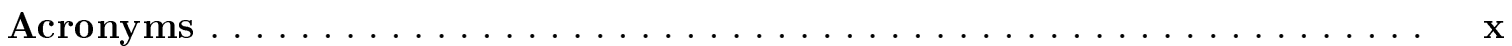

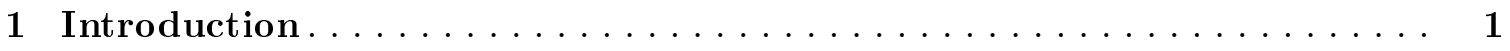

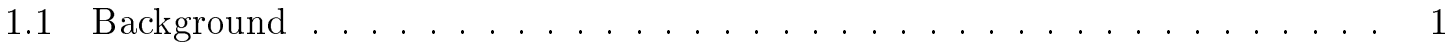

1.1.1 Introduction to acrylonitrile-butadiene-styrene thermoplastic . . . . . 1

1.1.2 ABS as a potential hybrid rocket fuel . . . . . . . . . . . 2

1.1.3 ABS as a base material for additive manufacturing . . . . . . . . . 3

1.1.4 Combustion and pyrolysis properties of ABS . . . . . . . . . . . 4

1.2 Literature Survey . . . . . . . . . . . . . . . . . . . . 5

1.2.1 Published scientific literature on hybrid motors and regression rate . . 5

1.2.1.1 Advantages and disadvantages of hybrid rocket motors . . . . 6

1.2.1.2 Attempts at determining regression rate . . . . . . . . . 7

1.2.2 Published scientific literature on additive manufacturing . . . . . . . . 9

1.2.3 Published scientific literature on pyrolysis experimentation techniques 10

1.2.3.1 Bulk pyrolysis methods . . . . . . . . . . . . . 10

1.2.3.2 Linear pyrolysis methods . . . . . . . . . . . . 10

1.2.4 Published scientific literature on ABS combustion properties . . . . . . 12

1.2.4.1 Fire and combustion studies . . . . . . . . . . . 13

1.2.4.2 Previous measurements of ABS activation energy at low heat

flux levels . . . . . . . . . . . . . . . 14

1.2.4.3 Arrhenius-type equations . . . . . . . . . . . 15

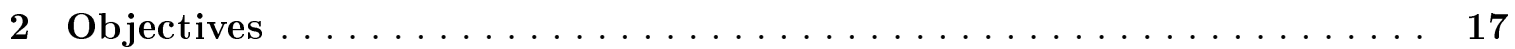

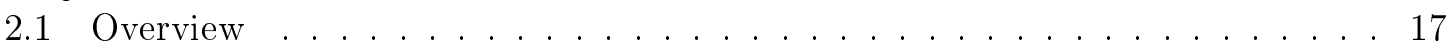

2.1.1 Statement of thesis . . . . . . . . . . . . . . . . . . 17

2.1 .2 Primary objectives . . . . . . . . . . . . . . 17

2.1.2.1 Determine regression rate vs. temperature Arrhenius-type curve for extruded and rapid-prototyped ABS past $500^{\circ} \mathrm{C} \quad . \quad 17$

2.1.2.2 Measure regression rate for extruded and rapid-prototyped ABS in inert nitrogen . . . . . . . . . . . . 18 
2.1.2.3 Calculate the activation energy for extruded and rapid-prototyped ABS ...................... 18

2.1.2.4 Verify the validity of Chiaverini et al.'s HTPB pyrolysis data 18

2.1.2.5 Compare data among extruded and rapid-prototyped ABS and HTPB . . . . . . . . . . . . . . . . 18

2.1 .3 Secondary objectives . . . . . . . . . . . . . . . . 18

2.1.3.1 Calculate heat of gasification for ABS . . . . . . . . 18

2.1.3.2 Determine differences in heat of gasification and regression rate between different types of ABS . . . . . . . . . 19

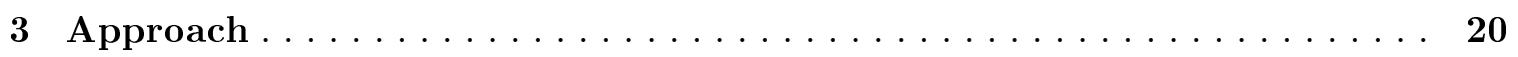

3.1 Analytical Methods: Calculating the Energy of Activation Using Regression

Rate Measurements . . . . . . . . . . . . . . . . . 20

3.2 Test Apparatus and Experimental Design Layout . . . . . . . . . . . . . . 22

3.2.1 Test cell design . . . . . . . . . . . . . . . . . . . . 23

3.2.2 Heating element design and analysis . . . . . . . . . . . . . . 24

3.2 .3 Mechanical apparatus design . . . . . . . . . . . . . . . 27

3.2.4 Test material description . . . . . . . . . . . . . . . . . . 28

3.2.5 Instrumentation Wiring and Control . . . . . . . . . . . . . . . . . 29

3.2.5.1 Rack and pinion wiring . . . . . . . . . . 30

3.2.5.2 Instrumentation wiring . . . . . . . . . . . . 31

3.2.5.3 Heater coil wiring . . . . . . . . . . . . . . . 32

3.3 Test Procedures . . . . . . . . . . . . . . . . . . . 35

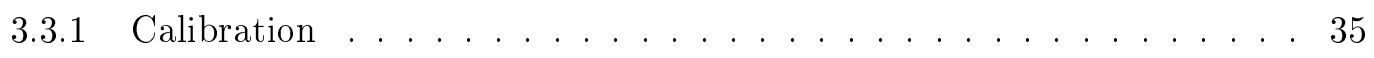

3.3 .2 Data collection . . . . . . . . . . . . . . 36

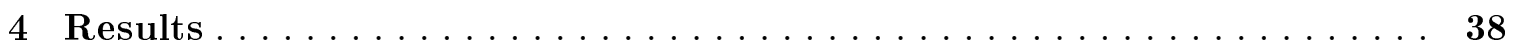

4.1 HTPB Results . . . . . . . . . . . . . . . . . . . . . . . . . . . . . . . . . .

4.2 ABS Results . . . . . . . . . . . . . . . . . . . 41

4.3 Comparison Between HTPB and ABS Results . . . . . . . . . . . . . 44

4.4 Error Analysis . . . . . . . . . . . . . . . . . . . 45

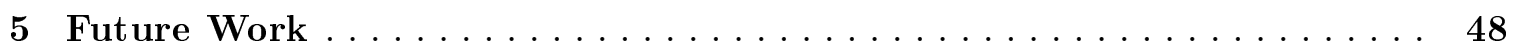

5.1 Heat Flux Measurements . . . . . . . . . . . . . . . . . . 48

5.2 Improvements to Thermocouple Mounting . . . . . . . . . . . . . . . . 49

5.3 Determining ABS Monomer Ratio . . . . . . . . . . . . . . . . 49

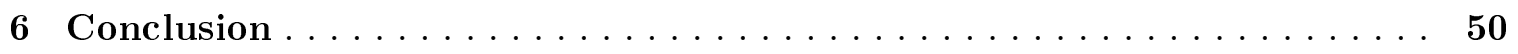

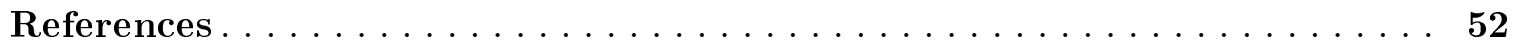




\section{List of Figures}

Figure $\quad$ Page

1.1 Unprocessed acrylonitrile-butadiene-styrene thermoplastic. (Wikimedia Com-

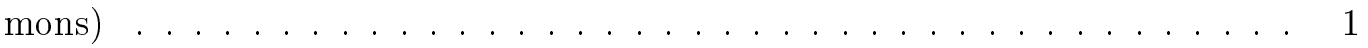

1.2 Two common uses for ABS: plumbing pipes (left), and children's toys (right). 2

1.3 Diagram of a 250,000 lbf (1.11 MN) hybrid rocket motor [1] . . . . . . . . 6

1.4 Structural formulae of acrylonitrile, butadiene, and styrene monomers. (Wikimedia Commons $\ldots \ldots \ldots \ldots$. . . . . . . . . . . . . 13

3.1 Functional block diagram of the test apparatus. . . . . . . . . . . . . 23

3.2 Test cell prior to heat shield installation. . . . . . . . . . . . . . . . . . 24

3.3 Time response plot for the heating of a mass of graphite using the Tempco Mightyband $^{\mathrm{TM}} \mathrm{MHC} 00045$ round coil heater. . . . . . . . . . . . 26

3.4 The operational heater being used to pyrolysize a sample of extruded ABS. $\quad 27$

3.5 Samples of rapid-prototyped ABS (left) and extruded ABS (right). . . . . . . 29

3.6 Wiring and control board. Not shown is the National Instruments NI 9472 24 volt digital output module. . . . . . . . . . . . . . . . . 30

3.7 Motor control wiring diagram. . . . . . . . . . . . . . . 31

3.8 Wiring diagram for the USB-6009 data acquisition unit. . . . . . . . . . . 32

3.9 Wiring diagram for the PST-5 AC to DC power converter. . . . . . . . . . 32

3.10 Wiring diagram for the solid-state relay block. . . . . . . . . . . . 33

3.11 Wiring diagram for the National Instruments NI $947224 \mathrm{~V}$ digital output source unit. . . . . . . . . . . . . . . . . . . 34

3.12 Wiring diagram for the Omega PST-8 power module. . . . . . . . . . . . 34

3.13 Panel display showing the deadband controller operating the coil heater. . . . 35

3.14 LabVIEW program used for recording and displaying test temperatures and regression. . . . . . . . . . . . . . . . . 37 
4.1 Results of the HTPB tests, with error bounds. . . . . . . . . . . . . . . 40

4.2 Comparison of Chiaverini et al.'s HTPB data (red) vs. the HTPB data from this report (blue). . . . . . . . . . . . . . . . . 41

4.3 Results of the extruded ABS tests, with error bounds. . . . . . . . . . . . . 42

4.4 Results of the rapid-prototyped extruded ABS tests, with error bounds. . . . 43

4.5 Results from all three test materials: HTPB (blue), extruded ABS (red), and rapid-prototyped ABS (black). . . . . . . . . . . . . . . . . 44

4.6 Time history of an HTPB test run with the error-reducing fitted line. . . . . . 46 


\section{List of Tables}

Table $\quad$ Page

1.1 Trait Comparison of Solid, Liquid, and Hybrid Rocket Systems [2] $\ldots \ldots \ldots$

3.1 Specifications of the Tempco Mightyband ${ }^{\mathrm{TM}}$ MCH00045 Round Coil Heater. . 26

3.2 Physical Description of the Test Samples Used in Experiments. . . . . . . . . 29

4.1 Estimates for Activation Energy and Heat of Vaporization of HTPB. . . . . . 45

4.2 Uncertainty Bounds on the Regression Rate, Activation Energy and Heat of Vaporization for HTPB and ABS at 95\% Confidence Level. . . . . . . . . . . 47 


\section{Acronyms}

$\begin{array}{ll}\text { ABS } & \text { Acrylonitrile-Butadiene-Styrene } \\ \text { AC } & \text { Alternating Current } \\ \text { CAD } & \text { Computer-Aided Design } \\ \text { CNC } & \text { Computer Numerically Controlled } \\ \text { DC } & \text { Direct Current } \\ \text { DSC } & \text { Differential Scanning Calorimetry } \\ \text { FDM } & \text { Fused Deposition Modelling } \\ \text { HTPB } & \text { Hydroxyl-Terminated Polybutadiene } \\ \text { RTV } & \text { Room Temperature Vulcanizing Silicone } \\ \text { PMMA } & \text { Polymethylmethacrylate } \\ \text { SAN } & \text { Styrene-Acrylonitrile } \\ \text { TGA } & \text { Thermogravimetric Analysis }\end{array}$




\section{Nomenclature}

$A \quad$ Arrhenius-type pre-exponenial factor, $\mathrm{s}^{-1}$

$A_{\text {evap }}$ Evaporation parameter, $\mathrm{s}^{-1}$

$A_{\text {reg }} \quad$ Regression rate parameter, $\frac{\mathrm{mm}}{\mathrm{s}}$

$A_{\text {surf }}$ Surface area, $\mathrm{m}^{2}$

$c_{p} \quad$ Specific heat, $\frac{\mathrm{J}}{\mathrm{kg} \cdot \mathrm{K}}$

$D_{\text {slug }}$ Diameter of the thermal mass used as part of the heater, $\mathrm{m}^{2}$

$E_{a} \quad$ Activation energy, $\frac{\mathrm{kJ}}{\mathrm{kg}}$ or $\frac{\mathrm{kJ}}{\mathrm{mol}}$

$h_{g} \quad$ Heat of gasification, $\frac{\mathrm{kJ}}{\mathrm{kg}}$ or $\frac{\mathrm{kJ}}{\mathrm{mol}}$

$h_{g}^{(e f f)}$ Effective heat of gasification, $\frac{\mathrm{kJ}}{\mathrm{kg}}$ or $\frac{\mathrm{kJ}}{\mathrm{mol}}$

$h_{v} \quad$ Heat of vaporization, $\frac{\mathrm{kJ}}{\mathrm{kg}}$ or $\frac{\mathrm{kJ}}{\mathrm{mol}}$

$k \quad$ Thermal conductivity, $\frac{\mathrm{W}}{\mathrm{m} \cdot \mathrm{K}}$

$L_{\text {slug }}$ Length of the thermal used as part of the heater, $\mathrm{m}$

$\dot{m} \quad$ Mass flow rate, or mass flux, $\frac{\mathrm{kg}}{\mathrm{s}}$

$m_{\text {slug }}$ Mass of the slug used as part of the heater, $\mathrm{kg}$

$q \quad$ Heat transfer rate, $\mathrm{W}$

$\vec{q}^{\prime \prime} \quad$ Three-dimensional heat flux, $\frac{\mathrm{W}}{\mathrm{m}^{2}}$

$\dot{r} \quad$ Regression rate, $\frac{\mathrm{mm}}{\mathrm{s}}$

$R_{u} \quad$ Universal gas constant, $8.3143 \times 10^{3} \frac{\mathrm{kJ}}{\mathrm{kg} \mathrm{mol} \cdot \mathrm{K}}$

$T \quad$ Absolute temperature, $\mathrm{K}$

$T_{a} \quad$ Ambient temperature, $\mathrm{K}$

$t_{\text {evap }}$ Time needed for complete evaporation, $\mathrm{s}$

$T_{g} \quad$ Glass transistion temperature, $\mathrm{K}$

$T_{\text {slug }}$ Temperature of the slug used as part of the heater, $\mathrm{K}$

$T_{\text {test }} \quad$ Temperature of test, $\mathrm{K}$

$\Delta H_{j}^{0} \quad$ Enthalpy of formation, $\frac{\mathrm{kJ}}{\mathrm{g} \cdot \mathrm{mol}}$ 
$\epsilon_{\text {slug }}$ Emmissivity of the thermal mass used as part of the heater

$\kappa \quad$ Rate constant

$\kappa_{\text {evap }}$ Evaporation constant

$\mu \quad$ Slope of the fitted line for an Arrhenius-type curve

$\rho_{\text {slug }}$ Density of the slug used as part of the heater, $\frac{\mathrm{kg}}{\mathrm{m}^{3}}$

$\sigma \quad$ Stefan-Boltzmann constant, $5.67 \times 10^{-8} \frac{\mathrm{W}}{\mathrm{m}^{2} \cdot \mathrm{K}^{4}}$ 


\section{Chapter 1 Introduction}

\section{$1.1 \quad$ Background}

\subsubsection{Introduction to acrylonitrile-butadiene-styrene thermoplastic}

Acrylonitrile-butadiene-styrene (ABS) is an inexpensive, recyclable thermoplastic that melts at relatively low temperatures and possesses excellent chemical, thermal, and mechanical properties $[3,4]$. ABS consists of three monomers: acrylonitrile, butadiene, and styrene. Acrylonitrile and styrene polymers provides rigidity to the plastic. Butadiene rubber adds toughness [5], making ABS resistant to cracking and warping. ABS has a high structural modulus $(2.3 \mathrm{GPa})$ and tensile yield strength $(45 \mathrm{MPa})$ [5]. This yield strength is about $38 \%$ of architectural aluminum [6]. ABS has been widely mass-produced for a variety of noncombustion applications, including household plumbing and structural materials. Figure 1.1 shows unprocessed ABS grains, while Figure 1.2 displays several common uses for ABS.

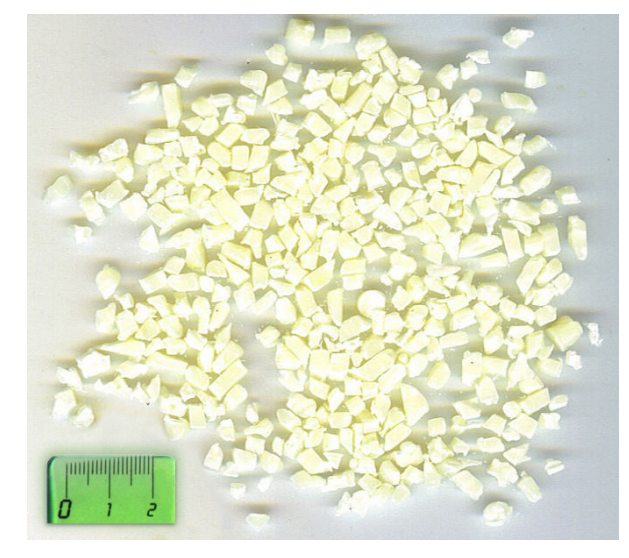

Fig. 1.1: Unprocessed acrylonitrile-butadiene-styrene thermoplastic. (Wikimedia Commons) 


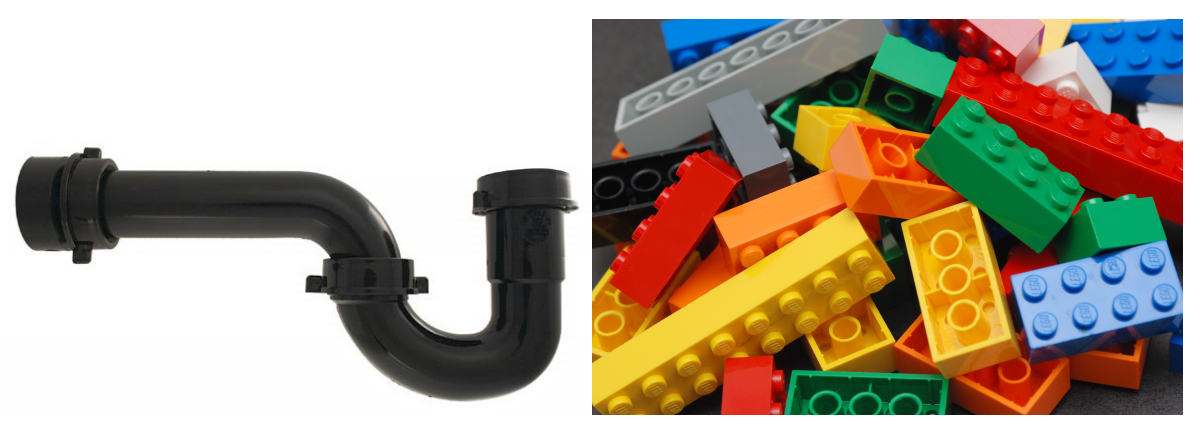

Fig. 1.2: Two common uses for ABS: plumbing pipes (left), and children's toys (right).

\subsubsection{ABS as a potential hybrid rocket fuel}

ABS has several mechanical properties that make it very attractive as a potential hybrid rocket fuel. Because ABS can be formed into a wide variety of shapes using modern additive manufacturing and rapid prototyping techniques, it is possible to embed complex highsurface area flowpaths within the fuel grain. These internal flowpaths can open up during a burn and allow for motor aspect ratios that are significantly shorter than can be achieved using conventional motor-casting technologies [7].

When subjected to heat ABS melts before vaporizing, which produces a liquid-film layer that provides a significant amount of film cooling along the burning surface. This insulating film layer directs the combustion heat toward the nozzle exit and allows the external motor case to remain cool during the burn [8]. This self-cooling property of ABS presents a highly significant advantage for in-space applications where thermal management is important.

ABS has a high heat distortion temperature [9], which means that fuel grain ports designed into an ABS motor are unlikely to collapse during operation. Because of the high structural modulus and yield strength, ABS could be used as a seeding material allowing the fuel grain to take a significant portion of the combustion chamber pressure load and reduce wall thickness requirements. Also, ABS resists creep and will retain its shape over long periods of time, due to the presence of the styrene monomer [9]. These same structural properties, as well as the self-insulating nature of ABS, allow for entire combustion chambers to be made from ABS. In addition, the toxicity of burning ABS has been shown to be less 
than that of burning various types of wood [10], meaning that ABS-fueled rockets would be safe to operate.

\subsubsection{ABS as a base material for additive manufacturing}

An emerging, potentially game-changing feature of ABS is its ability to be shaped into a wide range of geometries using additive manufacturing. Additive manufacturing, also known as rapid prototyping or material incress manufacturing [11], is the process where computercontrolled printheads are fed thermoplastic to build a previously-modeled part, layer by layer $[11,12]$. Since the late 2000s, interest in creating hybrid rocket motor engines using rapid prototyping has grown. Utah State University has been one of the first organizations to investigate the use of additive manufacturing in making hybrid rocket motors. Collaborating with other researchers, such as Fuller et al. at The Aerospace Corporation [13], Utah State has been actively researching materials that can potentially be used by rapid prototyping machines to create motors $[8,14]$.

When ABS melts, it forms an amorphous fluid before vaporizing. This "melting point", called the glass transition temperature is relatively low, about $110^{\circ} \mathrm{C}[15]$, and can be pre-

cisely controlled by measured heat addition to the material. This property allows ABS to be reshaped and recycled multiple times with little to no degradation of the material properties. Because of its melting point behavior, ABS has become the most popular material used in the additive manufacturing method known as fused deposition modeling (FDM). In FDM, a plastic filament is unwound from a coil and supplies material to an extrusion nozzle. The nozzle is heated to melt the material and can move in both the horizontal and vertical directions by a computer numerically controlled (CNC) mechanism. Exploiting the FDM process for ABS could revolutionize previous methods used to fabricate hybrid rocket fuel grains. FDM can support high production rates and offers the potential of improving hybrid fuel grain quality, consistency, and performance, while reducing development and production costs. More importantly, fuel grains can be fabricated with an almost infinite range of fuel port shapes, allowing for significant enhancement of burn properties and combustion efficiencies [13]. Many of these enhanced port shapes, such as an embedded helix, cannot 
be achieved with HTPB where "cast and cure" methods would not allow the cast tooling or mandrel to be removed after the grain is set.

\subsubsection{Combustion and pyrolysis properties of ABS}

Pyrolysis data, including activation energy $\left(E_{a}\right)$, heat of gasification $\left(h_{g}\right)$, and the pre-exponential factor $(A)$ vary widely among published literature and often carry high uncertainties. For example, $E_{a}$, which is the amount of energy needed to initiate combustion

in the ABS [16], is calculated to be about $150 \frac{\mathrm{kJ}}{\mathrm{mol}}$ to $270 \frac{\mathrm{kJ}}{\mathrm{mol}}$ by Jun et al. [17], 200 $\frac{\mathrm{kJ}}{\mathrm{mol}}$ by Wang and Zhang [18], and $220 \frac{\mathrm{kJ}}{\mathrm{mol}}$ by Li and Stoliarov [19]. Although Li and Stoliarov are one of the few who calculated Arrhenius coefficients for ABS, their published uncertainties are $40 \%$ [19]. Another problem is the paucity of thermal data for temperatures and heating rates that are within the operating range of hybrid motors. ABS pyrolysis tests are often conducted up to $600^{\circ} \mathrm{C}[18]$ at rates of at most $25^{\circ} \mathrm{C} / \mathrm{min}[20]$. The data collected under such conditions are not indicative of what is seen under real rocket motor firings, where temperatures reach over $1000^{\circ} \mathrm{C}$ and temperature gradients are on the order of $100,000^{\circ} \mathrm{C} / \mathrm{s}[21]$.

It appears that only one study has been performed to characterize the combustion properties of ABS as a hybrid rocket fuel. Whitmore, Peterson, and Eilers [14] investigated the combustion of ABS with nitrous oxide. In their analysis, they calculated the enthalpy of formation, $\Delta H_{j}^{0}$, using the "group addition" method developed by van Krevelen and Jijenhuis [22]. Assuming a mole fraction of $50 \%$ butadiene, $43 \%$ acrylonitrile, and $7 \%$ styrene, Whitmore, Peterson, and Eilers calculated $\Delta H_{j}^{0}$ to be $62.63 \frac{\mathrm{kJ}}{\mathrm{g} \cdot \mathrm{mol}}$, a value $140 \%$ higher than the corresponding value for HTPB [14]. This leads to their assertion that ABS will likely not burn as hot as HTPB. However, this study did not evaluate the heat of gasification for ABS, and value used in their analysis (2.3 $\left.\frac{\mathrm{MJ}}{\mathrm{kg}}[23]\right)$ was based on the combustion data measured for industrial (and possibly fire-retarded) ABS formulations at significantly lower heat flux levels than would be experienced during hybrid rocket combustion.

Thus, a major data gap exists with regard to pyrolysis data for ABS, especially at high heat flux levels. Detailed high heat flux pyrolysis tests are required to fill in these data. 
Chiaverini et al. [24] performed a set of pyrolysis experiments on HTPB that produced pyrolysis data from regression rate $(\dot{r})$ measurements. The test procedure used by Chiaverini et al. involved dropping a heated copper rod onto samples of HTPB. Thermocouples were attached to the copper-HTPB interface. This reports details a similar test stand setup that will perform the same experiment as Chiaverini et al. on ABS.

\subsection{Literature Survey}

A review of published scientific literature is necessary to understand the pyrolysis data needed to use ABS in rocket propulsion systems. First, since ABS is being investigated primarily for use as a hybrid rocket fuel, an overview of hybrid rocket motors is presented. A brief look at additive manufacturing follows. A summary of scientific literature on ABS and its combustion properties is also requisite to comprehending gaps in ABS research. Finally, in order to conduct ABS pyrolysis experiments, previous research on the subject is examined.

\subsubsection{Published scientific literature on hybrid motors and regression rate}

Sutton and Biblarz [1] defined hybrid propulsion as a propulsion system where one propellant component is stored in a fluid phase, while the other is stored in a solid phase. Typically, the fuel grain is solid and the oxidizer is a fluid, although there are exceptions [25]. Like other forms of rocket propulsion, hybrid motor combustion is self-sustaining [26]. Hybrid propulsion was studied as early as the 1930s, with the first successful hybrid rocket

being flown in 1933 by the Russians Sergei Korolev and Mikhail Tikhonravov [27]. Figure 1.3 shows a drawing of a large hybrid rocket motor developed during the 1980s. 


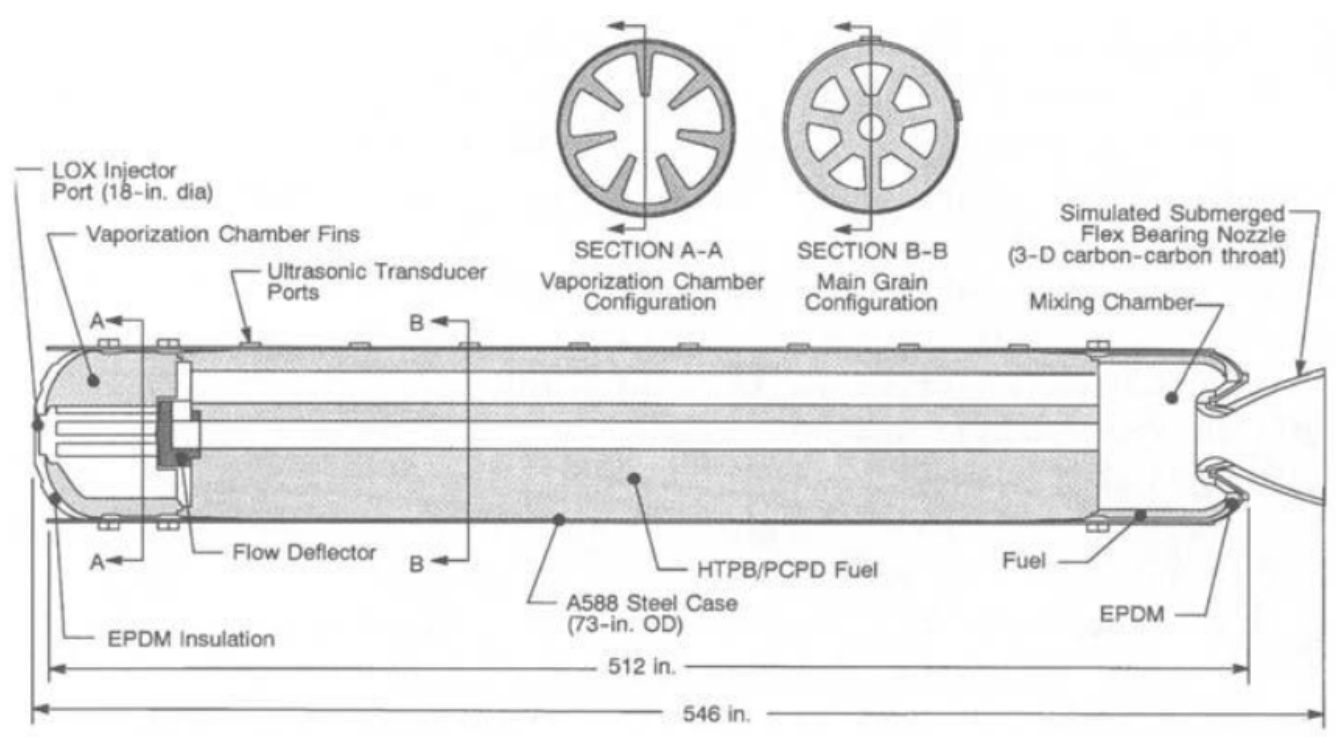

Fig. 1.3: Diagram of a 250,000 lbf (1.11 MN) hybrid rocket motor [1].

\subsubsection{Advantages and disadvantages of hybrid rocket motors}

Hybrid propulsion has some key advantages over solid and liquid propulsion systems, as noted by Altman and Holzman [27]. First, hybrid rockets are inherently safer than solid or liquid rockets, as the fuel grains in a hybrid rocket are inert. Engine throttling and shutdown is less complicated in hybrid rockets than in liquid rockets because the fuel flow rate will automatically adjust for any slowdown in oxidizer flow. Thus, thrust termination can be achieved by shutting off the liquid flow. Also, hybrid fuel grains are less sensitive to temperature and grain imperfections, and are cheaper to manufacture than solid fuel grains. Kuo and Chiaverini [25] also added that hybrid rockets have greater maneuverability with controlled thrust profiling over a wide range of operating conditions.

However, a key weakness of hybrid motors is the low regression rates of the fuel [27, 28]. Regression rate is defined as the rate at which solid fuel is converted into a gas [29]. Chiaverini [30] asserted that regression rate is the key parameter influencing hybrid fuel grain design. The first, and arguably the most influential [29], researchers to publish regression rate models were Marxman and his co-workers (Gilbert [26], Wooldridge [31], and Muzzy [31]). Marxman and Gilbert theorized that reactions in a hybrid motor occur between very thin 
"flame sheets" at some small distance above the fuel grain [26]. This led to the assumption that fuel concentrations are linear functions of the velocity profile within the flame region. Marxman, Wooldridge, and Muzzy further showed that the reaction kinetics and radiative heat transfer are of secondary importance in so-called pure systems (no oxidizer was mixed with the fuel grain) [31]. Research done by Williams [32] also showed that for fuels with large activation energies (another trait of a pure system), the burning rate of the solid, a close analog of the regression rate, is identical with that of a premixed gaseous combustible. Table 1.1 shows a comparison among solid, liquid, and hybrid rocket systems. This table came originally from work done by Bath [2].

Table 1.1: Trait Comparison of Solid, Liquid, and Hybrid Rocket Systems [2]

\begin{tabular}{c|ccc} 
Trait & Solid & Hybrid & Liquid Bi-Propellant \\
\hline Command shutdown and throttle capability & No & Yes & Yes \\
Non-toxic combustion exhaust & No & Yes & Yes \\
Ease of transport, storage, and handling & No & Yes & Yes \\
Maintenance and launch processing cost & Moderate & Low & Moderate to high \\
Manufacturing cost & Moderate & Low & Moderate to high \\
Readily scalable & Yes & Yes & No \\
Specific impulse & Good & Good & Excellent \\
Propellant mass fraction & Good & Fair & Excellent \\
Safe, non-explosive propellants & No & Yes & Can be minimized
\end{tabular}

\subsubsection{Attempts at determining regression rate}

Smoot and Price [33] conducted experiments on regression rate where the flow rate, fuel and oxidizer composition, and pressure varied. Their results verified Marxman, Wooldridge, and Muzzy's assumption [31] that radiative heat transfer is small for high flow rate systems. Smoot and Price also discovered that at low flow rates, convective heat transfer becomes minimal and regression rate becomes independent of pressure and more dependent on mass flow rate [33]. Regression rates in high flow rate regimes were shown to be the opposite, 
independent of mass flux and proportional to pressure. Kosden and Williams [34] agreed with Smoot and Price's assessment of regression rate dependence, but warned that actually predicting the regression rate would be difficult, due to the problems in determining the density of the fuel vapor at the fuel grain wall.

One criticism of the work done by Marxman et al. is the difficulty in determining the required fluid parameters, thus forcing researchers to come up with empirical models to calculate regression rate [35]. Researchers actively tried to remedy this shortcoming. Houser [36] reasoned that since regression rate results from a chemical reaction, measuring regression rate would be the same as measuring the rates of the chemical reactions creating chamber combustion. Houser then derived equations that allowed for the calculation of regression rate based on pyrolysis data and mass flow, $\dot{m}$. Lengellé [37] expanded on this work and came up with empirical data for polymethylmethacrylate (PMMA, also known as Plexiglas ${ }^{\circledR}$ ) that matched predicted degradation values but underestimated regression rate. Chiaverini et al. [38] also validated the importance of mass flux in regression rate calculations, but disputed Marxman, Wooldridge, and Muzzy's assertion [31] that radiative heat transfer is negligible in high mass flow systems. Pastrone [39] notes that there are limits to mass flux, as too high mass flow rates could potentially extinguish the flame, while too little mass flux could lead to subsurface fuel melt and flame instability. Chiaverini et al. also contended that chemical reaction processes were not as important in calculating regression rate as was the shedding of mass from the solid fuel surface. Eilers and Whitmore [35] presented a regression rate model that balanced the chemical kinetics with the convective heat transfer at the surface of the fuel grain. Another mass flow model was given by Whitmore and Chandler [40], designed specifically for self-pressuring systems running nitrous oxide.

Researchers have been actively looking into better methods for enhancing regression rate in hybrid motors. Karabeyoglu, Altman, and Cantwell [28] observed that regression rates could be enhanced by increasing the amount of liquid fuel that is shed during motor operation, a phenomenon known as entrainment. Entrainment is pressure independent and can be described using a knowledge of the fuel's degradation kinetics [41]. Additives to 
the fuel, such as paraffin wax [8,28], metallic particles like aluminum [24,39], and other compounds such as ammonium nitrate [27] and ammonium perchlorate [39], have been shown to successfully drive up surface regression. Turbulence generators have been tested, as an increase in turbulence at the burning surface will increase the heat transfer coefficient [27]. Swirl injectors, end-burning hybrids, vortex hybrids, and multi-port fuel grains were also been developed to enhance hybrid fuel regression rates [30].

\subsubsection{Published scientific literature on additive manufacturing}

Additive manufacturing, also known as rapid prototyping or material incress manufacturing [11], has been a fantasy of industrialists since the late 1940s [42]. However, commercial viability has only been attainable since 1993 [43]. Additive manufacturing was developed specifically to speed up the process of part creation and prototyping. Pieces that would take a skilled craftsman weeks or months to make could be made in hours by using rapid prototyping [44]. There are many different types of rapid prototyping machines, but all utilize the same design process. The piece being manufactured is first modeled in a 3D CAD software package, usually in mathematically-sectioned slices $[12,44]$. The solid model is then tessellated and exported to the manufacturing machine as an .stl file. A variety of materials can be used to create parts, including plastics and foodstuffs [13]. The solid model is easily disseminated, removes human errors associated with reading manufacturing blueprints, and eliminates the extra cost that usually comes with intricate parts [45].

The material incress method used at Utah State University is the FDM method mentioned previously. An FDM machine consists of a movable head that deposits small beads of molten material onto a substrate. The plastic is heated to $0.5^{\circ} \mathrm{C}$ above its melting point, so that the beads (called roads) cool in 0.1 seconds and effectively cold weld themselves to previous layers [44]. Roads as small as 0.05 millimeters in diameter are possible with FDM [46]. Any kind of thermoplastic or heat-fusible material can be used in FDM, but the most common material used since 1994 has been ABS [43]. Fused-deposited ABS retains many of its properties, but Hoekstra, Kraft and Newcomer [46] showed that ABS parts can lose up to half of their tensile and flexural strength, depending on the orientation of the 
piece.

\subsubsection{Published scientific literature on pyrolysis experimentation techniques}

\subsubsection{Bulk pyrolysis methods}

The importance of solid, detailed chemistry in hybrid rocket motor technology has long been underappreciated [47]. Gascoin et al. notes that good chemical data, in the form of accurate pyrolysis and combustion parameters, would simplify the tedious process of choosing an oxidizer/fuel system [47]. What data are known about hybrid rocket fuels comes from traditional or "bulk heating" pyrolysis experiments, such as TGA and DSC. TGA, or thermogravimetric analysis, was first described in 1963 by Coats and Redfern [48]. TGA consists of a sample that is continuously weighed while being heated to a specific temperature. The results of a TGA run are either a weight vs. temperature curve or a rate of weight loss vs. temperature curve. DSC, or differential scanning calorimetry, was developed in the early 1960s by Watson and O'Neill [49]. During DSC, a sample is placed in a heat exchanging relationship with an external medium. The machine then measures the amount of power it takes for the sample to reach thermal equilibrium. In both TGA and DSC, polymer samples are usually exposed to heating rates on the order of $0.1-25^{\circ} \mathrm{C} / \mathrm{s}[20,21]$ and temperatures up to about $400-600^{\circ} \mathrm{C}$ [18]. Atmospheres within the test enclosures are usually inert [19] or pure oxygen [50].

\subsubsection{Linear pyrolysis methods}

While bulk heating methods have their uses, the data derived from these tests are not applicable in hybrid rocket propulsion. Part of the problem lies in the fact that bulk heating methods are used to study polymer degradation, which is independent of the atmosphere type, rather than polymer combustion, where the atmosphere composition is important [51]. McAlevy and Hansel [50] observed that the atmospheric environments bulk heating methods use may produce different pyrolytic conditions than are found in hybrid propulsion systems. Beck [52] noted that the mild pyrolytic conditions hybrid rocket fuels are subjected to are 
insufficient to characterize the propellant's combustion during a motor firing. McAlevy and Blazowski [53] also found that melting and charring temperatures are different in bulk heating tests than in rocket combustion conditions. The development of melt and char are of primary importance for a hybrid fuel, as melt layers [28] and carbonaceous char layers [54] may affect motor performance. Finally, Bouck, Baer, and Ryan [21] observed that slower heating rates could modify the sample material before it reaches its target temperature. Thus, whatever data were collected from the bulk test would be measuring a different material than what would be seen in a rocket motor firing.

To correct these problems, researchers began developing procedures that focused on linear pyrolysis, rather than bulk heating. For present purposes, the term "linear pyrolysis" is considered synonymous with "surface regression", or the linear regression of a fuel under combustion conditions [55]. Linear pyrolysis experimentation was started by Schultz and Dekker in 1955. Their work, detailed in Reference [56], is the basis for all subsequent linear pyrolysis studies. Schultz and Dekker created a device that would lower a sample of solidified ammonium chloride onto a heated high-silica (Vycor) glass plate and allowed the sample to decompose. Thermocouples were attached to the plate and the ammonium chloride rod immediately after each run to gather temperature data. This was the beginning of the so-called "hot-plate method". Barsh et al. [57] improved upon this design by integrating the thermocouples into the heating element and adding a linear potentiometer to improve regression data. Chaiken et al. [58] conducted experiments with PMMA that seemed to verify this method of pyrolysis.

The hot plate method, however, has been criticized on several fronts. McAlevy, Lee, and Smith [59] noted that hot plate method samples may be subjected to surface erosion, temperature discontinuity at thermocouple junctions, and thermo-chemical interactions at the sample-plate boundary. Nachbar and Williams [60] observed that the assumptions underlying hot plate thermal analysis may imply that total pressure and gaseous reactant partial pressures have a negligible impact on regression rate, which is a questionable assertion at best. Gas-film effects in hot-plate experiments were observed by Cantrell $[61,62]$ that may 
affect the pyrolysis data, but these findings were challenged by Andersen [63].

Several different linear pyrolysis methods were created to overcome the shortcomings of the hot plate method. Nachbar and Williams [60] created a modified hot plate test stand where the heated plate was made from porous material instead of impervious glass. These authors surmised that having a porous plate would allow for the test atmosphere to permeate through, better simulating one dimensional flow. McAlevy and Hansel [50] replaced the hot plate altogether with the plume of a lit rocket motor. This design was successfully tested on samples of PMMA. McAlevy and Hansel also reported one experiment that used a jet of diffused flaming oxidizer as a heat source [50]. Schultz and Dekker, in the same paper where they outlined the hot plate method, also talked about replacing the hot plate with a heated wire [56]. These procedures offered improvements over previous designs, but there is disagreement over how effective they are $[24,50,59,61,63]$.

\subsubsection{Published scientific literature on ABS combustion properties}

ABS is a thermoplastic resin first commercialized in the 1950s and is composed of three kinds of monomers: acrylonitrile, butadiene, and styrene [9], which are depicted in Figure 1.4. In the creation of ABS, acrylonitrile and styrene is co-polymerized into styreneacrylonitrile (SAN). Butadiene is then dissolved into the SAN to create ABS [5]. Typical ABS preparations contain 21\%-27\% acrylonitrile, $12 \%$ - $25 \%$ butadiene, and 54\%-63\% styrene [9]. Acrylonitrile improves ABS's overall chemical resistance, butadiene imparts impact resistance, and styrene supplies good proccessability and stiffness [9]. 


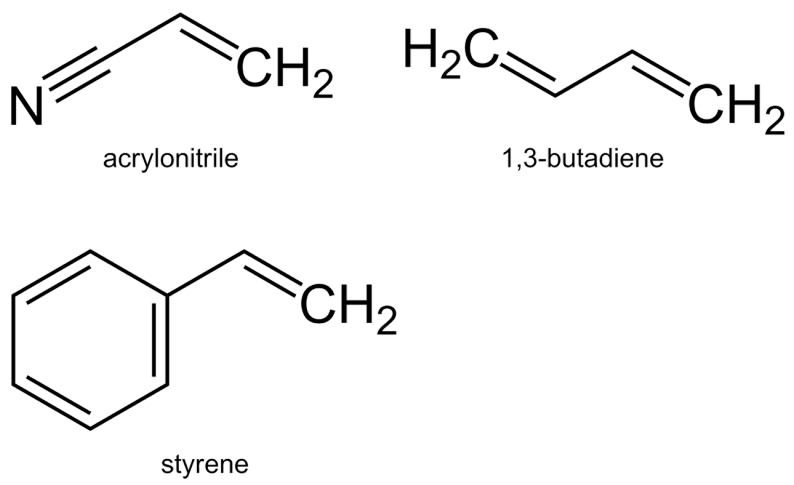

Fig. 1.4: Structural formulae of acrylonitrile, butadiene, and styrene monomers. (Wikimedia Commons)

\subsubsection{Fire and combustion studies}

Most research performed on ABS has been done in the realm of fire safety. In the 1980s literature surveys performed by Levin [64], and Rutkowski and Levin [10] established the toxicity and number of combustion products of ABS. Rutkowski and Levin noted the presence of carbon monoxide and hydrogen cyanide when ABS burned in an oxidative atmosphere [10]. These two compounds were listed as the most toxic compounds to evolve from combusting ABS, but were shown to be less toxic than the byproducts of burning Douglas fir or red oak. Levin [64] counted 27 different types of molecules created from degrading ABS, but none were in sufficient quantities to pose significant toxicological risk.

Improving ABS's ability to withstand fire has also been a popular topic of study. ABS has been shown to generate very high numbers of semivolatile compounds during thermal degradation [5]. ABS has intrinsic flammability [3], due to butadiene's susceptibility to oxidative degradation [15]. Camino, Costa, and Luda di Cortemiglia [65] showed that ABS will char when burned in an oxidative environment. Char, as defined by these authors, is the residue formed by the decomposition of the polymer. The char layer is thermally stable and will inhibit further degradation and combustion, thus acting as a fire retardant [65].

The understanding of how ABS degrades while it combusts was studied by Suzuki and Wilkie [66]. They showed that the degradation of ABS can be understood by studying the 
breakdown of its constituent parts: polyacrylonitrile, polybutadiene, polystyrene, and SAN. Suzuki and Wilkie also noted that ABS degradation in a pure nitrogen environment begins around $340^{\circ} \mathrm{C}$ with the formation of butadiene monomer. Wilkie and McKinney [51] found that aromatics begin to form at $350^{\circ} \mathrm{C}$, signaling the beginning of SAN degradation. In contrast, ABS burned in air degrades in two steps, as detailed by Shapi [67]: the first begins at $300^{\circ} \mathrm{C}$, in which $89 \%$ of the $\mathrm{ABS}$ is converted into volatile compounds; the second step occurs at about $450^{\circ} \mathrm{C}$, which volatilizes the remaining $11 \%$ of the sample. At temperatures higher than $450^{\circ} \mathrm{C}$, the evolution of styrene becomes more important [66], and with increasing heat SAN begins to dominate the degradation process [68]. In both cases, acrylonitrile evolves in a narrow window between $400^{\circ} \mathrm{C}$ and $450^{\circ} \mathrm{C}[66]$.

\subsubsection{Previous measurements of ABS activation energy at low heat flux levels}

Several studies have sought to establish values for the activation energy, $E_{a}$, of ABS. Yang used TGA to estimate ABS's activation energy to be $32.0 \frac{\mathrm{kcal}}{\mathrm{mol}}\left(134 \frac{\mathrm{kJ}}{\mathrm{mol}}\right)$ in an oxygen environment, $34.4 \frac{\mathrm{kcal}}{\mathrm{mol}}\left(144 \frac{\mathrm{kJ}}{\mathrm{mol}}\right)$ in air, and $42.7 \frac{\mathrm{kcal}}{\mathrm{mol}}\left(179 \frac{\mathrm{kJ}}{\mathrm{mol}}\right)$ in pure nitrogen [69]. Yen, Lee, and Yang [70] used the same technique to calculate $E_{a}$ to be $179.3 \frac{\mathrm{kJ}}{\mathrm{mol}}$ in nitrogen, but serious doubts were raised by Marcilla and García-Quesada [71] on the procedures used to derive this number. According to Marcilla and García-Quesada, Yen, Lee, and Yang improperly used pyrolysis data and committed several errors in assigning and using variables. The values Yen, Lee, and Yang calculated for $E_{a}$ are therefore invalid. Because both Yang and Yen, Lee, and Yang used the same technique in their papers, Marcilla and García-Quesada's rebuttal casts doubt on Yang's values, as well. Using a variety of analytical methods, Jun et al. calculated ABS's activation energy to be anywhere from $59.9 \frac{\mathrm{kJ}}{\mathrm{mol}}$ to $270.7 \frac{\mathrm{kJ}}{\mathrm{mol}}$ [17], a range that is intolerably large. In their own opinion, Jun et al. felt that the range was probably more like $150 \frac{\mathrm{kJ}}{\mathrm{mol}}$ to $270 \frac{\mathrm{kJ}}{\mathrm{mol}}$, a narrower range to be sure, but still not specific enough for accurate estimates of hybrid rocket motor performance. Li and Stoliarov used TGA and DSC to derive an $E_{a}$ value of $219 \frac{\mathrm{kJ}}{\mathrm{mol}}$, but the authors reported a temporary loss of thermal contact during the DSC experiment [19]. Their numbers must be corroborated before their data can be trusted. Finally, Wang and Zhang calculate $E_{a}$ to be $196.6 \frac{\mathrm{kJ}}{\mathrm{mol}}[18]$, 
a value that only adds to the confusion.

\subsubsection{Arrhenius-type equations}

A few papers also tried to establish kinetic parameters for ABS, especially the parameter A. "Arrhenius-type" equations follow the form of the original Arrhenius Equation,

$$
\kappa=A \exp \left(-\frac{E_{a}}{R_{u} T}\right)
$$

where the Greek letter $\kappa$ is the rate constant, $A$ is the frequency factor, $E_{a}$ is the activation energy, $R_{u}$ is the universal gas constant, and $T$ is absolute temperature [16]. $A$ can be viewed as the number of molecular collisions per second in a piece of material, regardless of whether those collisions lead to a reaction [18]. Li and Stoliarov calculated $A$ to be $1 \times 10^{14} \mathrm{~s}^{-1}$, with an error bound of $40 \%$ [19]. Yen, Lee, and Yang calculated $A$ to be $3.07 \times 10^{7} \mathrm{~s}^{-1}$ [70], although Marcilla and García-Quesada's stinging rebuke of these authors' technique throw their number into doubt [71]. Wang and Zhang's estimate of $A$ was $3.06 \times 10^{12} \mathrm{~s}^{-1}$ [18].

Calculating $h_{g}$ has been equally problematic. Although a single value for $h_{g}$ is desirable, such a value, according to Staggs, would be merely an idealization, not an actual characteristic of ABS [72]. Staggs noted that an average value of $h_{g}$, or $h_{g}^{(e f f)}$, could be used in first-order analysis of polymers that do not form char. However, ABS does forms a char

layer, inhibiting the steady burning behavior assumed in deriving $h_{g}^{(e f f)}$. Staggs did observe that while for small temperature gradients $h_{g}$ is coupled with the heating rate, for infinitely high temperature gradients $h_{g}^{(e f f)}$ becomes independent of heating rate. This would allow meaningful mass flux (or regression rate) data to be calculated for ABS placed under hybrid rocket motor operating conditions [73].

The literature on hybrid motors using ABS is sparse. Palmer [73] compared ABS hybrid motor performance with polypropylene and PMMA motors. Palmer noted that ABS had higher regression rates than either of the other polymers, but had a lower specific impulse than polypropylene. Whitmore, Peterson, and Eilers [14] tested ABS alongside HTPB and showed that ABS performed slightly worse and had lower regression rates than HTPB. 
However, ABS burned more consistently and had better manufacturing precision. ABS is easier to construct with multiple ports and sophisticated port geometries, which will enhance regression rate and improve performance [14]. 


\section{Chapter 2 Objectives}

\section{$2.1 \quad$ Overview}

\subsubsection{Statement of thesis}

This research will use methodologies similar to Chiaverini et al.'s to assess pyrolysis data from HTPB and extruded and rapid-prototyped ABS. These data will represent some of the first attempts to characterize ABS's pyrolysis and combustion properties in the temperature and heat flux regions experienced by hybrid rocket motor propulsion systems.

\subsubsection{Primary objectives}

\subsubsection{Determine regression rate vs. temperature Arrhenius-type curve for extruded and rapid-prototyped ABS past $500^{\circ} \mathrm{C}$}

This is the most important objective of the experimentation. If an accurate Arrheniustype curve can be created for both extruded and rapid-prototyped ABS, the data needed to meet many of the other objectives listed here will fall out naturally. These curves will also serve as an easy way for future researchers to compare their results with the ones presented in this report. $500^{\circ} \mathrm{C}$ was chosen as the starting point because almost all other investigations of ABS stopped at this temperature. Combustion processes occur well past this point. This research will fill in the gaps between the bulk pyrolysis tests and what is needed for proper hybrid rocket motor performance modeling. 


\subsubsection{Measure regression rate for extruded and rapid-prototyped ABS in inert nitrogen}

Accurate regression rate data for ABS are essential when using ABS in a hybrid rocket motor. This objective will be met if the objective listed in Section 2.1.2.1 is met.

\subsubsection{Calculate the activation energy for extruded and rapid-prototyped ABS}

Activation energy is used to compare the performance of different types of fuels. Lower values of $E_{a}$ signify better burning fuels. $E_{a}$ is directly analogous to the heat of vaporization, as can be seen in Section 3.1. This objective will be met using the data generated by the Arrhenius-type curve from Section 2.1.2.1.

\subsubsection{Verify the validity of Chiaverini et al.'s HTPB pyrolysis data}

As a precursor to the ABS work, an Arrhenius-type curve will be made for HTPB samples. The HTPB will come from a batch that was successfully used as a hybrid rocket motor fuel grain. If the shape of the curve matches the curve produced by Chiaverini et al. in Reference [24], the experimental design as a whole will be validated and will also verify the actual values for regression rate and activation energy calculated by Chiaverini et al.

\subsubsection{Compare data among extruded and rapid-prototyped ABS and HTPB}

Since the work done by Whitmore, Peterson, and Eilers [14] appears to be the only direct comparison between ABS and HTPB as potential rocket fuel sources, the data generated by this experiment will help refine the analytical results in that paper.

\subsubsection{Secondary objectives}

\subsubsection{Calculate heat of gasification for ABS}

Since the heat of gasification is only indirectly deduced from the data generated from this experiment, success will not hinge on whether good heat of gasification values can be found. However, heat of gasification numbers would be most beneficial for future ABS hybrid 
motor research. The biggest potential problem of the results from Whitmore, Peterson, and Eilers is the over-estimation of $h_{g}$. This led to lower-than-expected burn efficiencies [14]. Therefore, deducing the heat of gasification will be attempted as part of the experiment in the hopes that the results from Whitmore, Peterson, and Eilers can be updated.

\subsubsection{Determine differences in heat of gasification and regression rate be- tween different types of ABS}

If the objectives listed in Sections 2.1.2.2 and 2.1.3.1 are met, then a comparison between extruded and rapid-prototyped ABS will be attempted. 


\section{Chapter 3}

\section{Approach}

\subsection{Analytical Methods: Calculating the Energy of Activation Using Regres- sion Rate Measurements}

An Arrhenius-type equation is used to derive the pyrolysis data. The form of this equation parallels Equation 1.1, but instead of a rate constant $\kappa$ the regression rate $\dot{r}$ is used [24]:

$$
\dot{r}=A_{r e g} \exp \left(-\frac{E_{a}}{R_{u} T}\right)
$$

where $A_{\text {reg }}$ is the regression rate parameter. Taking the natural logarithm to both sides,

$$
\ln \dot{r}=\ln A_{r e g}-\frac{E_{a}}{R_{u} T},
$$

allows for the creation of a semi-log plot. The slope of the plot determines the activation energy, while the y-intercept of the plot gives the regression rate parameter.

The heat of gasification is defined as the heat required to produce a unit mass of volatile products from a unit mass of a solid, at standard temperature and pressure [72]. Mathematically, heat of gasification is defined as

$$
h_{g}=\int_{T_{a}}^{T_{g}} c_{p}(T) d T+h_{v}
$$

where $T_{g}$ is the glass transition temperature, $T_{a}$ is ambient temperature, $c_{p}(T)$ is the specific heat of ABS as a function of temperature, and $h_{v}$ is the heat of vaporization or latent heat of gasification and represents the heat per unit mass required to entirely vaporize the material starting at $T_{g}$. Since ABS is an amorphous material, it has no true melting point. Depending on the monomer ratio present in the material, $T_{g}$ can vary from $105^{\circ} \mathrm{C}$ to $120^{\circ} \mathrm{C}[67,74]$. 
The lack of a crystalline structure for ABS means that $T_{g}$ is taken to the be the temperature at which the solid polymer softens and begins to transition to a liquified state. The integral in Equation 3.3 represents the heat per unit mass required to heat the material to its glass transition point. Peydró Rasero et al. showed that the specific heat of ABS is fairly constant over the range of $100^{\circ} \mathrm{C}-300^{\circ} \mathrm{C}\left(2.72 \frac{\mathrm{kJ}}{\mathrm{kg} \cdot \mathrm{K}}\right)$ [74]. Since the glass transition temperature of ABS lies well within this range, Peydró Rasero et al.'s observations allow the integral in Equation 3.3 to be directly evaluated as

$$
\int_{T_{a}}^{T_{g}} c_{p}(T) d t=c_{p} \cdot\left(T_{g}-T_{a}\right)
$$

Brennan, Shapiro, and Watton [75] observed that the heat of vaporization of volatile liquids can be calculated by using an Arrhenius-type equation:

$$
\kappa_{\text {evap }}=A_{\text {evap }} \exp \left(-\frac{h_{v}}{R_{u} T}\right)
$$

where $\kappa_{\text {evap }}$ is the evaporation constant and $A_{\text {evap }}$ is the evaporative parameter. The evaporation constant $\kappa_{\text {evap }}$ is equal to the inverse of the time needed for complete evaporation,

$$
\kappa_{\text {evap }}=\frac{1}{t_{\text {evap }}}
$$

Dimensional analysis shows that $E_{a}$ and $h_{v}$ are analogous to each other. If Equation 3.1 is divided through by $\dot{r}$ and Equation 3.5 is divided through by $\kappa_{\text {evap }}$, both resulting equations will be equal to 1 and can thus be set equal to each other:

$$
\frac{A_{\text {reg }}}{\dot{r}} \exp \left(-\frac{E_{a}}{R_{u} T}\right) \sim \frac{A_{\text {evap }}}{\kappa_{\text {evap }}} \exp \left(-\frac{h_{v}}{R_{u} T}\right)
$$

Dimensionally, the quotients $\frac{A_{r e g}}{\dot{r}}$ and $\frac{A_{\text {evap }}}{\kappa_{\text {evap }}}$ are unitless, and can thus be ignored. Taking the natural logarithm to both sides of Equation 3.7 liberates the expressions inside of the exponentials:

$$
-\frac{E_{a}}{R_{u} T} \sim-\frac{h_{v}}{R_{u} T}
$$


Since $R_{u}$ and $T$ are common to both sides, all that is left is $E_{a} \sim h_{v}$. Thus, it is shown that the activation energy and the heat of vaporization have the same dimensions.

\subsection{Test Apparatus and Experimental Design Layout}

The test apparatus used by Chiaverini et al. consisted of several parts [24]. A furnace located on top of the structure was used to heat a $12.7 \mathrm{~mm} \times 76 \mathrm{~mm}$ ( $0.5 \mathrm{in} \times 3$ in) cylindrical copper mass. The furnace was connected to a series of ball valves that led directly to the HTPB sample The ball valves would open and close in sequence to allow the coppper mass to drop without flooding the test cell with heat from the furnace.. Thermocouples were mounted to the sample at several places. A complicated nitrogen purge system was used to carry the products of combustion away from the sample viewing area. The entire setup was then placed in a sealed pyrolysis chamber. A window was installed so a camera could be trained on the HTPB to measure regression rate.

This design serves as the basis for the ABS test stand. However, the ABS apparatus is both simpler and more accurate. Instead of dropping a heated mass onto a test sample, the sample is lowered by way of a motorized rack and pinion sled. The drive motor is attached to the rack and pinion sled gearing and applies a small torque to the mechanism to keep the test element in contact with the heater as it regresses during pyrolysis. A linear potentiometer is embedded along the drive track, allowing for real-time in-situ regression rate measurements. This is more accurate than the camera setup used by Chiaverini et al. Since the present design is not interested in analyzing the products of combustion, the purge system lost much of its complexity. By reducing the sophistication of Chiaverini et al.'s design, the current design gains robustness and allows for rapid construction and calibration. Figure 3.1 shows a block diagram of the test stand layout. 


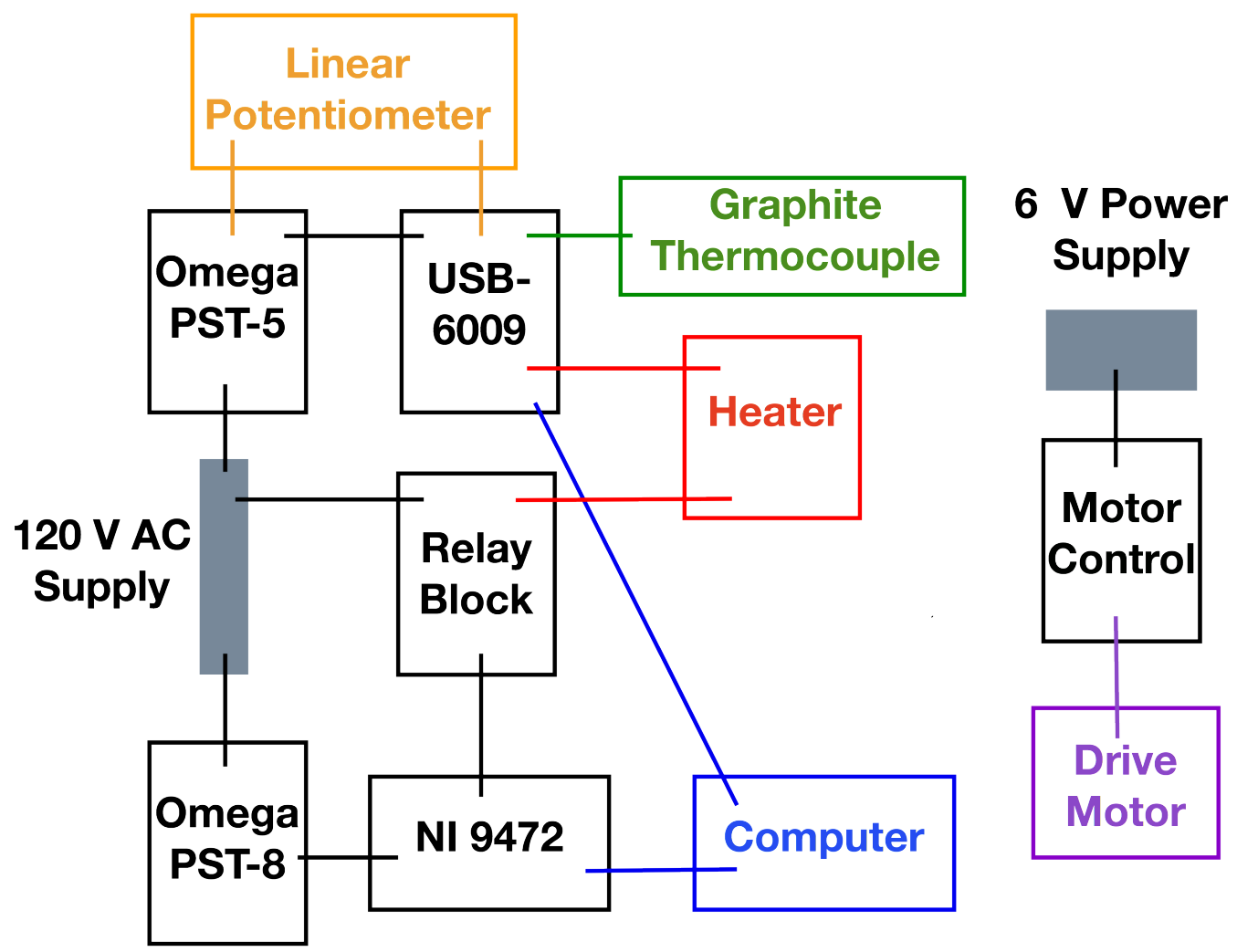

Fig. 3.1: Functional block diagram of the test apparatus.

\subsubsection{Test cell design}

The walls and bottom of the test cell are made with aluminum sheets because it is cheap, durable, and able to withstand the temperatures involved with pyrolysis. It is attached to extruded aluminum T-slotted framing with generous amounts of room temperature vulcanizing silicone (RTV). The test cell provides a stable, heat-resistant structure for easy mounting of the rack and pinion, as well as the heater. The test cell is placed inside of an acrylic display case, which helps maintain an inert atmosphere and isolates the test stand from outside influences. Figure 3.2 shows the outer structure of the test cell. 


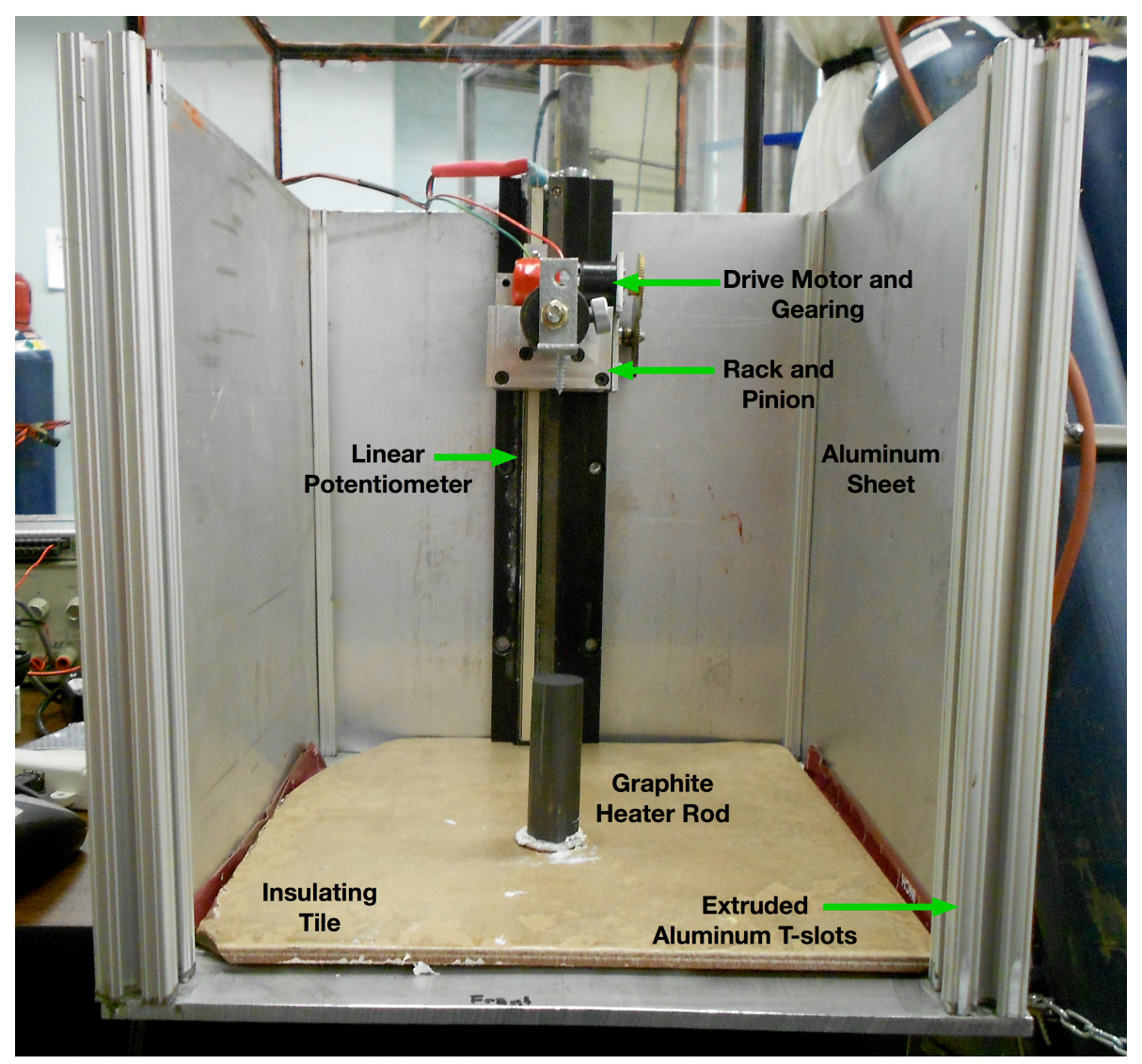

Fig. 3.2: Test cell prior to heat shield installation.

\subsubsection{Heating element design and analysis}

A custom high-heat load output heater system was designed for this experiment. Available commercial cartridge heaters in the required wattage ranges were beyond this experiment's budget and lacked the necessary form factor. The designed heater consists of two parts, a heating element and a thermal mass that ensures the ABS sample is uniformly pyrolysized. The heating element must be small enough to fit in the test chamber, yet powerful enough to heat the thermal mass up to $1000^{\circ} \mathrm{C}$. Using the lumped capacitance method [76], temperature can be related to the power output of the heater and the size of the thermal mass. Since the experiment is in a still atmosphere, convection heating can reasonably be neglected. The Biot number is estimated to be about 0.1 , well within the requirements of 
the lumped capacitance method. The heat output is then determined by Equation 3.9:

$$
m_{\text {slug }} c_{p_{\text {slug }}} T_{\text {test }}=q-\epsilon_{\text {slug }} \sigma A_{\text {surf }}\left(T_{\text {slug }}^{4}-T_{a}^{4}\right)
$$

where $m_{\text {slug }}$ is the mass of the thermal mass, $c_{p_{s l u g}}$ is the specific heat of the thermal mass, $T_{\text {test }}$ is the temperature the test is conducted at, $q$ is the heat transfer rate in watts, $\epsilon_{\text {slug }}$ is the emissivity of the thermal mass, $\sigma$ is the Stefan-Boltzmann constant $\left(5.67 \times 10^{-8} \frac{\mathrm{W}}{\mathrm{m}^{2} \cdot \mathrm{K}^{4}}\right)$, $A_{\text {surf }}$ is the surface area of the thermal mass, $T_{\text {slug }}$ is the outer temperature of the thermal mass, and $T_{a}$ is the ambient temperature. $m_{\text {slug }}$ can be written as

$$
m_{\text {slug }}=\rho_{\text {slug }} L_{\text {slug }} \frac{\pi D_{\text {slug }}^{2}}{4}
$$

where $\rho_{\text {slug }}$ is the density of the thermal mass, $L_{\text {slug }}$ is the length of the thermal mass, and $D_{\text {slug }}$ is the diameter of the thermal mass. Also, $A_{\text {surf }}$ can be expressed as

$$
A_{\text {surf }}=\pi D_{\text {slug }} L_{\text {slug }}+\frac{\pi D_{\text {slug }}^{2}}{4} \approx \pi D_{\text {slug }} L_{\text {slug }}
$$

Substituting Equations 3.10 and 3.11 into Equation 3.9, Equation 3.12 is derived:

$$
T_{\text {test }}=\frac{4}{\rho_{\text {slug }} c_{p_{\text {slug }}} D_{\text {slug }}}\left[\frac{q}{L_{\text {slug }} \pi D_{\text {slug }}}-\epsilon_{\text {slug }} \sigma\left(1+\frac{D_{\text {slug }}}{4 L_{\text {slug }}}\right)\left(T_{\text {slug }}^{4}-T_{a}^{4}\right)\right] .
$$

When comparing the different commercially-available heaters using Equation 3.12, it becomes apparent that reaching the high temperatures required for this experiment is a delicate balance between heat output and thermal mass size. The optimum balance seems to be a heat output $q$ of about $700 \mathrm{~W}$, a thermal mass diameter of $2.5 \mathrm{~cm}$, and a thermal mass length of about $7.5 \mathrm{~cm}$. The only type of heaters capable of reaching these requirements are round wire heaters. These heaters consist of a thick wire wound in a helix that easily slips over the thermal mass. The one selected for this experiment is the Tempco Mightyband ${ }^{\mathrm{TM}}$ MHC00045 round coil heater. Figure 3.3 shows a projected time response plot of a graphite mass being heated with the same specifications, displayed in Table 3.1, as 
the Tempco heater.

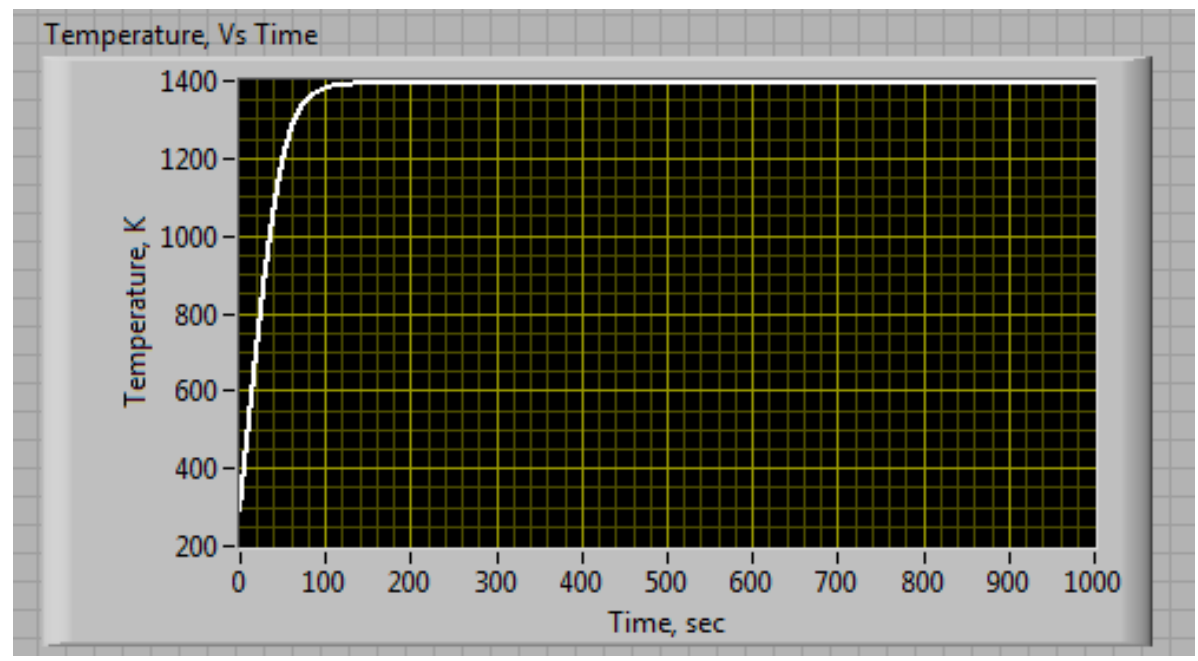

Fig. 3.3: Time response plot for the heating of a mass of graphite using the Tempco Mightyband ${ }^{\mathrm{TM}}$ MHC00045 round coil heater.

Table 3.1: Specifications of the Tempco Mightyband ${ }^{\mathrm{TM}}$ MCH00045 Round Coil Heater.

\begin{tabular}{|ll|}
\hline Height: & $50.8 \mathrm{~mm}(2 \mathrm{in})$ \\
Inner Diameter: & $22.2 \mathrm{~mm}(7 / 8 \mathrm{in})$ \\
Outer Diameter: & $28.3 \mathrm{~mm}(11 / 8 \mathrm{in})$ \\
Wattage: & $670 \mathrm{~W}$ \\
Sheath Material: & Alloy 600 (Inconel) \\
Imbedded Thermocouple: & Type K \\
Voltage: & $120 \mathrm{~V}$ \\
\hline
\end{tabular}

Chiaverini et al. used a heated copper thermal mass for their thermal analysis of HTPB [24]. Copper was selected because it has a large specific heat capacitance and high thermal conductivity. However, for the temperature range under consideration for ABS analysis, copper's melting temperature is too low. Graphite is used instead, as it has a higher melting point, an adequate thermal conductivity (roughly $130 \frac{\mathrm{W}}{\mathrm{m} \cdot \mathrm{K}}$ [77]), and a large specific heat (roughly $700 \frac{\mathrm{J}}{\mathrm{kg} \cdot \mathrm{K}}$ [78]). As noted by Null, Lozier, and Moore [79], the thermal 
conductivity of graphite depends on the orientation of the plane of deposition as well as the temperature to which the graphite is heated. However, since the lumped capacitance method is valid, directional variations in $k$ will not affect the amount of heat delivered to the test sample. K-type thermocouples are mounted just below the graphite surface to provide temperature readings. The graphite thermal mass has a slightly larger diameter than the ABS sample, so that minimal melting plastic contaminates the heating element. The graphite is mounted to the bottom of the test cell with a screw. The cell bottom rests on a sheet of glass to prevent any heat from the screw from melting the acrylic base of the display case. A photograph of the operational heater in contact with a material sample is shown in Figure 3.4 .

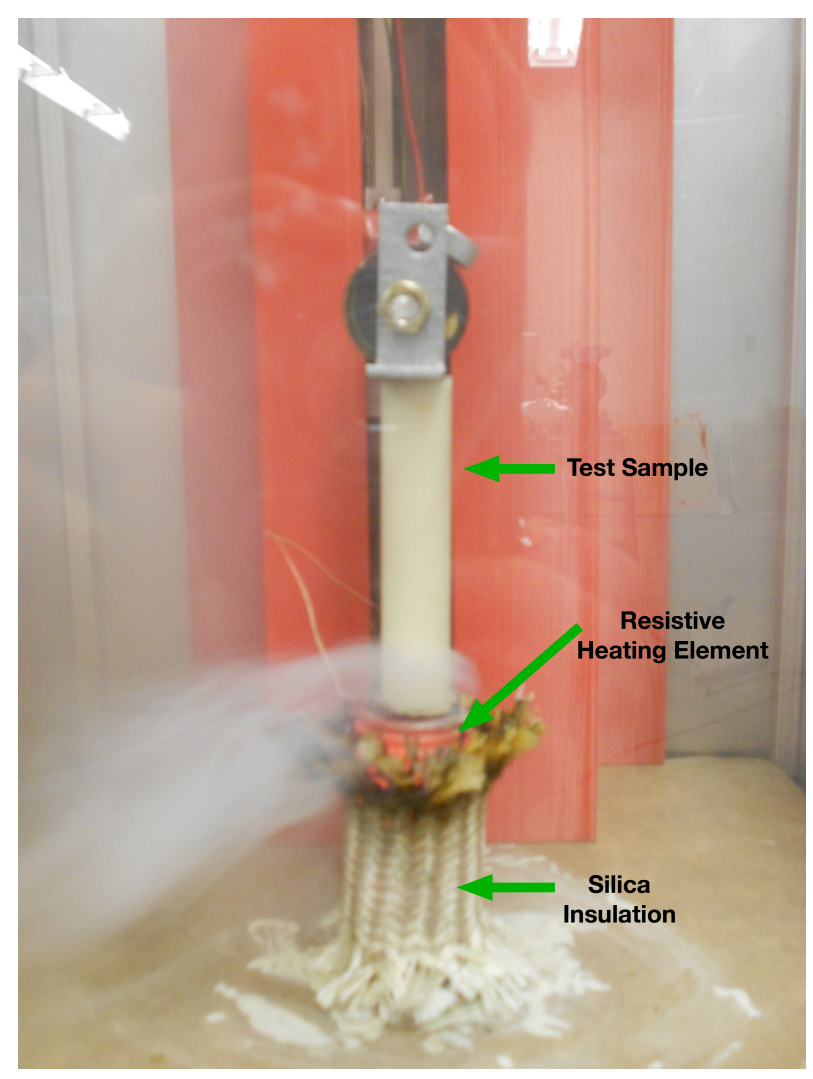

Fig. 3.4: The operational heater being used to pyrolysize a sample of extruded ABS.

\subsubsection{Mechanical apparatus design}

Samples are attached to a motorized rack and pinion. A linear potentiometer coupled 
with the rack and pinion measures the movement of the mounted ABS while in contact with the heater. This gives a direct in situ measurement of the regression rate. A visualization control system implemented in National Instruments's LabVIEW ${ }^{\circledR}$ helps ensure the ABS has solid contact with the heater at all times during the test. A rapid-prototyped ABS heat shield protects the potentiometer from the heat.

Nitrogen gas is used to purge the test cell during and after every test. If normal atmospheric conditions were used, the pyrolysis of ABS would not be affected. However, oxygen significantly lowers the operating temperature of the graphite, thus creating the need for an inert environment. Using nitrogen also eliminates any risk of reactions with the combustible byproducts of ABS. The low pressures from the nitrogen feed allows for simple plumbing and prevents damage from potential over-pressurization. This air flow will clean out any soot or smoke obscuring the viewing area. Smoke and soot are ventilated through a loose-fitting acrylic lid.

\subsubsection{Test material description}

Samples of rapid-prototyped ABS, extruded ABS, and HTPB are used for testing. Both types of ABS, shown in Figure 3.5, are approximately $20 \mathrm{~mm}$ in diameter and $75 \mathrm{~mm}$ in length. The rapid-prototyped ABS samples are made using the Stratasys Fortus $250 \mathrm{mc}^{\mathrm{TM}}$. Samples of HTPB were taken from scrap material from a previous motor casing and were of varying lengths and widths. These variations in the dimensions of the HTPB samples are non-consequential since only linear regression is measured. Table 3.2 describes the physical properties of both kinds of ABS and HTPB. Since Hoekstra, Kraft, and Newcomer showed that variations exist in material properties of ABS samples created by FDM [46], there could be variations between extruded ABS and rapid-prototyped ABS. Quantifying these variations, if any, is needed to fully characterize ABS for use as a hybrid rocket fuel. 


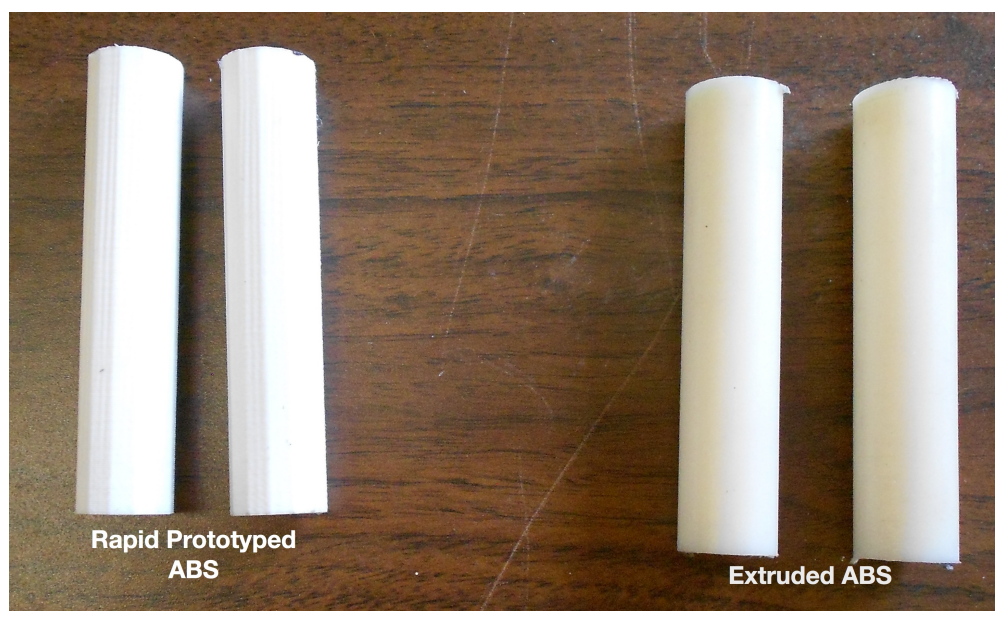

Fig. 3.5: Samples of rapid-prototyped ABS (left) and extruded ABS (right).

Table 3.2: Physical Description of the Test Samples Used in Experiments. HTPB Extruded ABS Rapid-Prototyped ABS

\begin{tabular}{cccc}
\hline Density & $935 \frac{\mathrm{kg}}{\mathrm{m}^{3}}$ & $1025 \frac{\mathrm{kg}}{\mathrm{m}^{3}}$ & $971 \frac{\mathrm{kg}}{\mathrm{m}^{3}}$ \\
Length & $75 \mathrm{~mm}$ & $75 \mathrm{~mm}$ & $75 \mathrm{~mm}$ \\
Mass & $13 \mathrm{~g}$ & $15 \mathrm{~g}$ & $14 \mathrm{~g}$ \\
Color & Dark gray & Cream & White
\end{tabular}

\subsubsection{Instrumentation Wiring and Control}

Minimal instrumentation is required for the test apparatus, creating a simple wiring scheme. The major wiring components are the motorized rack and pinion sled, instrumentation (thermocouples and linear potentiometer), and the heater coil. Figure 3.6 shows the wiring and control board used by the test stand. The modules in Figure 3.6 are represented by black squares in Figure 3.1. 


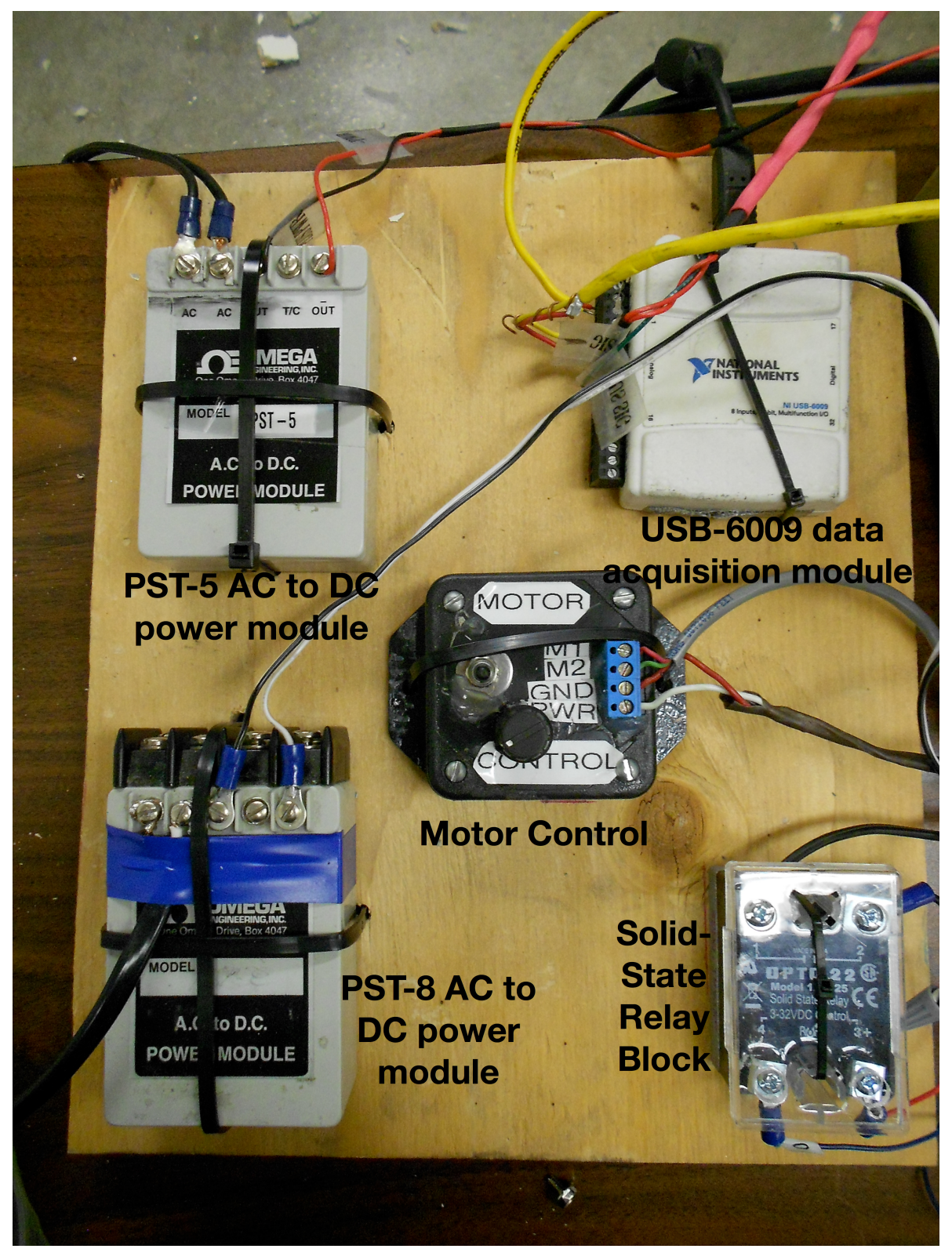

Fig. 3.6: Wiring and control board. Not shown is the National Instruments NI 947224 volt digital output module.

\subsubsection{Rack and pinion wiring}

The rack and pinion sled motor requires a 6 volt DC power source to operate. The 6 volt power supply is connected to the motor control block. The block contains a potentiometer to modulate the input voltage, and a switch to command the sled motor to position the sled 
up or down. The sled motor is then wired to the control block. The motor is represented by the purple block on the far right of Figure 3.1. Figure 3.7 is the wiring diagram for the motor control system.

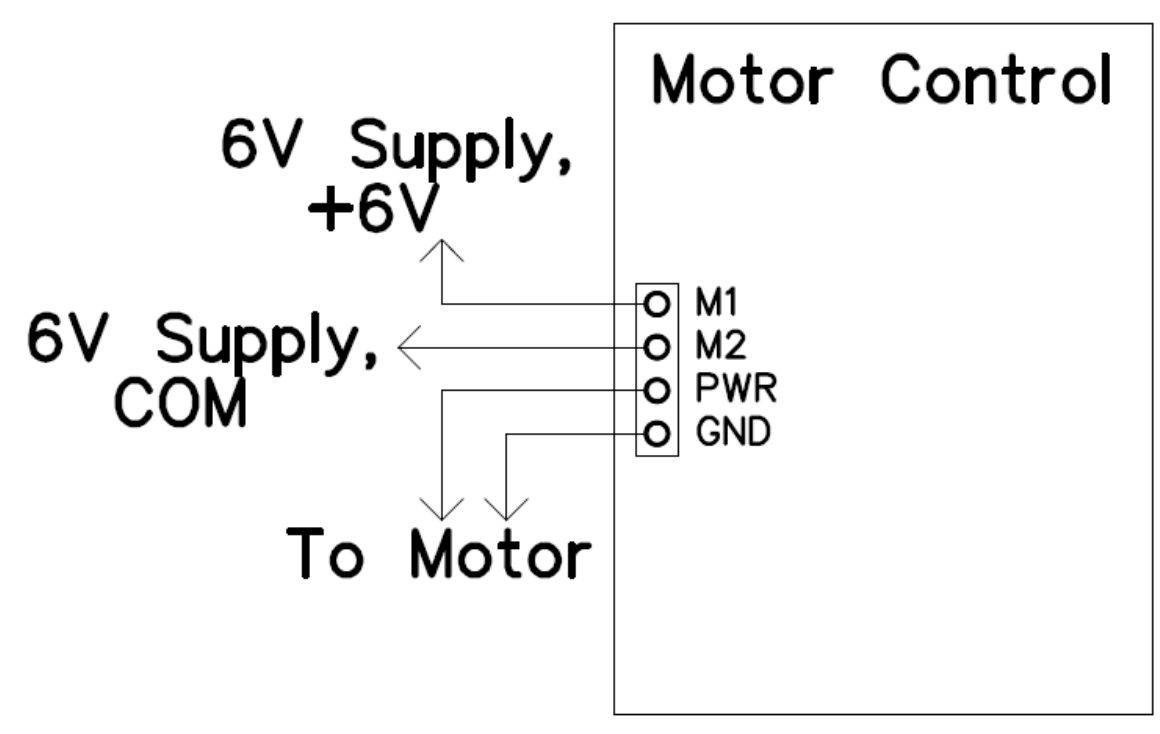

Fig. 3.7: Motor control wiring diagram.

\subsubsection{Instrumentation wiring}

Thermocouples to the heater coil and graphite are wired into a National Instruments USB-6009 analog data acquisition module, along with the measurement leads of the linear potentiometer. This is represented in the upper-middle section of Figure 3.1. This module then connects to the computer via USB. In addition, the linear potentiometer requires a 5 volt DC power supply. Power is provided by connecting an output terminal on an Omega PST-5 AC to DC power module to a lead of the linear potentiometer. Subsequently, a lead from the PST-5 connects to the USB-6009, converting 120 volt AC power into 5 volt DC. Figure 3.8 shows the wiring diagram for the USB-6009 and Figure 3.9 shows the wiring for the PST-5. 


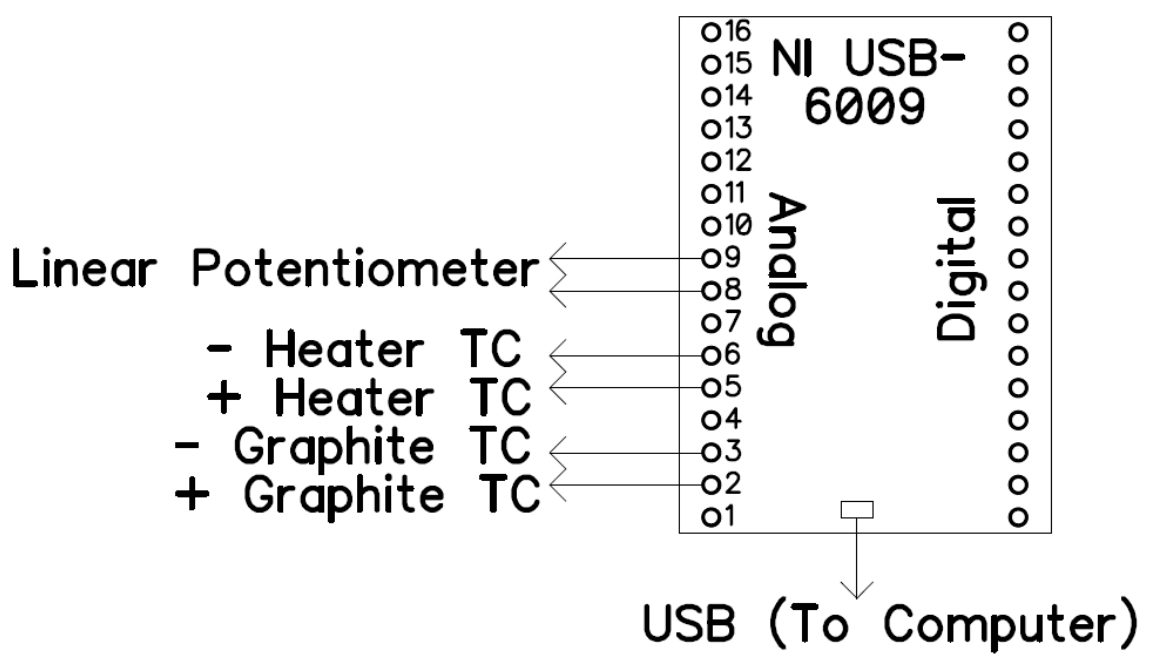

Fig. 3.8: Wiring diagram for the USB-6009 data acquisition unit.

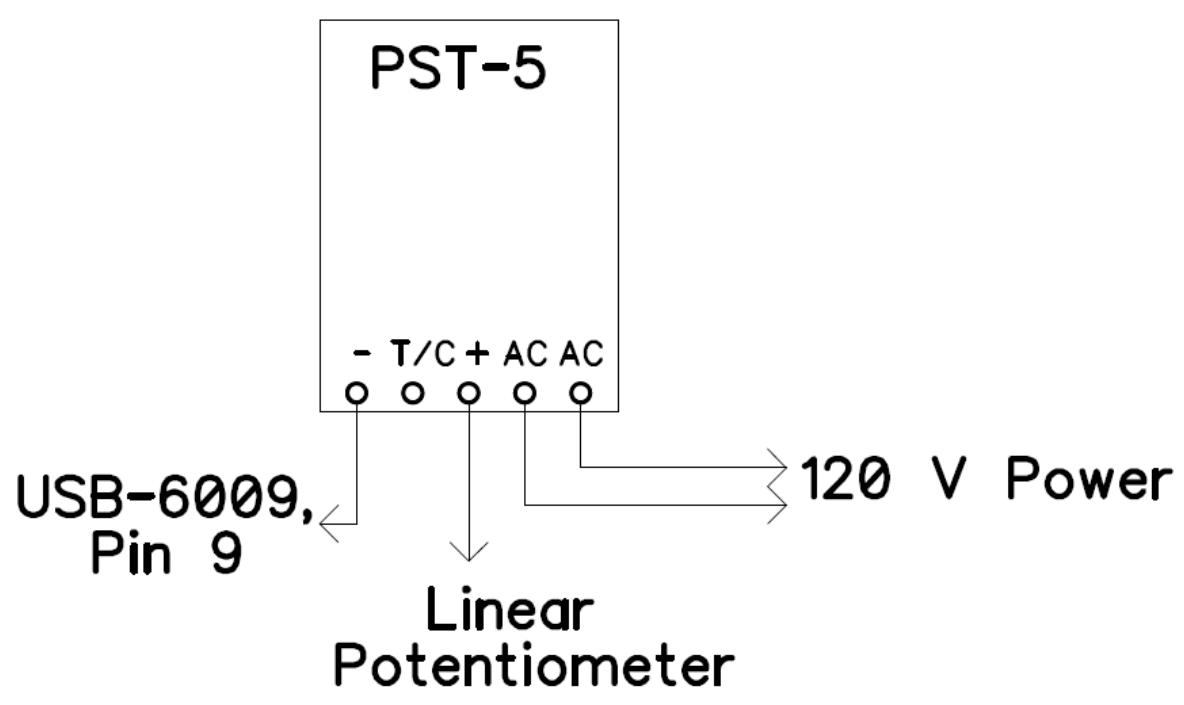

Fig. 3.9: Wiring diagram for the PST-5 AC to DC power converter.

\subsubsection{Heater coil wiring}

The heater coil has the most complicated wiring scheme. In addition to requiring 120 $\mathrm{V}$ AC, the heater coil must have a relay system controlled by a computer so when the graphite reaches the desired temperature range, the heater will switch off. Then, when the graphite temperature reads below the desired temperature range, the heater will turn on. 
This is accomplished by wiring one heater coil lead into a solid state relay block, then wiring one lead of the power cable (plugged into the 120 volt source) into the opposite side. The remaining leads of the coil and source are then mated together with a wire nut. The relay is powered by a National Instruments NI 947224 volt DC digital output source unit. The NI 9472 in turn is powered by a PST- 8120 volt AC to 8 volt DC power module. The NI 9472 connects to the computer by USB cable, and receives its input commands from the program that monitors the heater temperature. The wiring diagrams for the relay block, the NI 9472, and the PST-8 are shown in Figures 3.10-3.12.

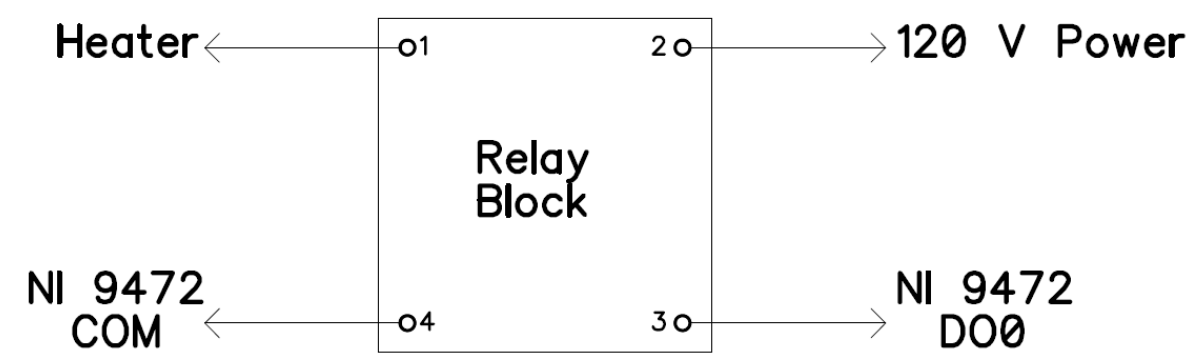

Fig. 3.10: Wiring diagram for the solid-state relay block. 


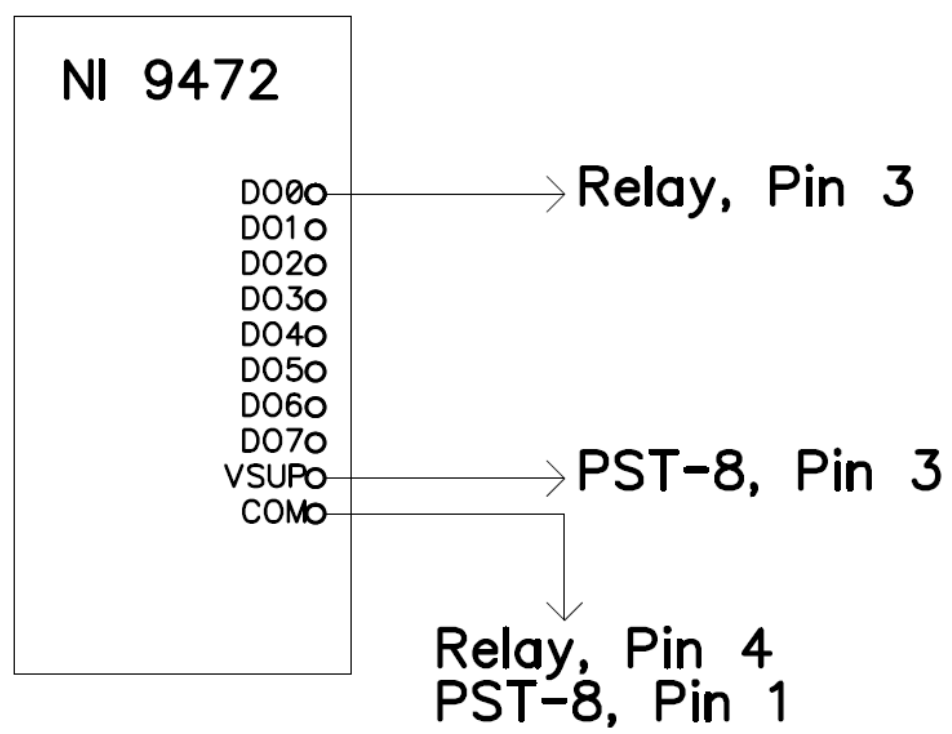

Fig. 3.11: Wiring diagram for the National Instruments NI 947224 V digital output source unit.

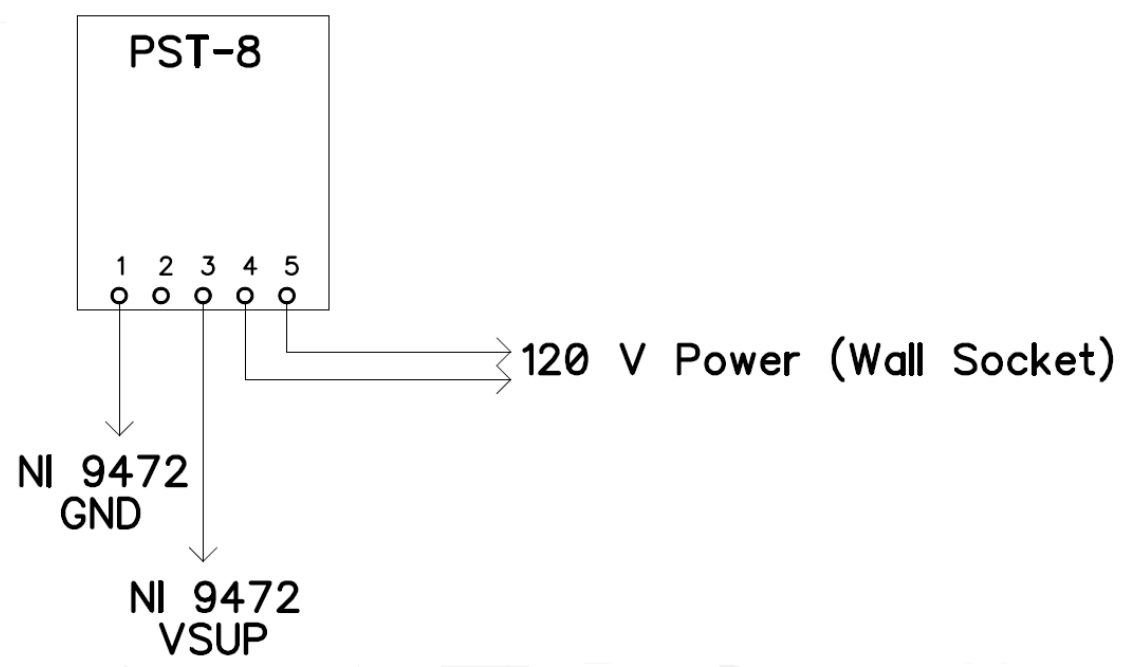

Fig. 3.12: Wiring diagram for the Omega PST-8 power module.

A deadband controller is used to control the heater. Once a test temperature is selected, a deadband region was applied. Once the graphite heater reached the upper bounds of the deadband, the coil heater would turn off. The coil heater would stay off until the temperatures dipped below the lower bound of the deadband. When calibrating the system, 
a $5^{\circ} \mathrm{C}$ deadband was applied to either side of the set temperature. During tests, the deadband limits were relaxed to $10^{\circ} \mathrm{C}$. Figure 3.13 shows the deadband controller operating the coil heater.

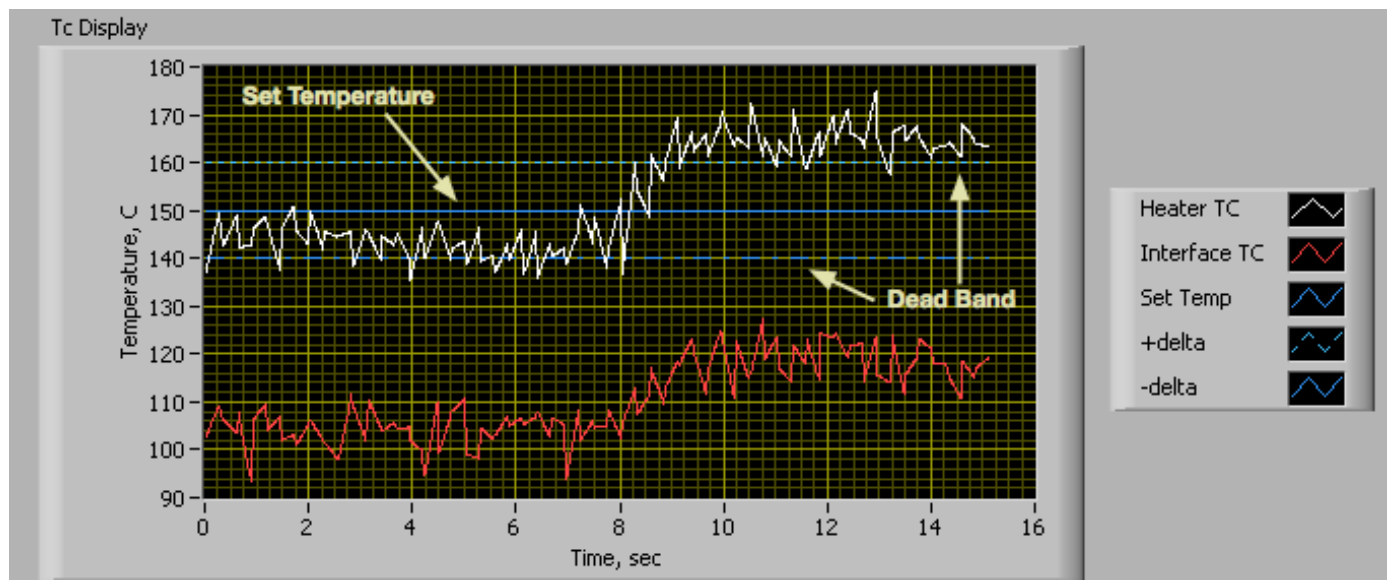

Fig. 3.13: Panel display showing the deadband controller operating the coil heater.

\subsection{Test Procedures}

\subsubsection{Calibration}

Proper calibration of the heating system is essential before experimental tests are conducted. The unpowered heater is placed in a cold water bath, and temperature is recorded using the built-in thermocouple. The procedure is repeated for the graphite thermocouple. These readings are then compared with those of a glass thermometer that is also measuring the temperature of the water. Calibration procedures are repeated with a hot water bath. Once deviations from the glass thermometer are fixed, both thermocouples are considered calibrated and the system is ready for testing. Before subsequent tests, the thermocouples measure ambient air temperature in comparison to a digital thermometer. If either thermocouple is biased, corrective action is taken before testing, minimizing the bias error.

The rack and pinion is calibrated once before any testing starts. A length scale on the side of the rack and pinion measures the distance to the bottom of the test cell. The sled is placed at a certain position, then a LabVIEW program records the voltage across the linear 
potentiometer associated with that position. The linear potentiometer exhibits a slightly non-linear position measurement response that is accounted for using a second order curve fit. Very little position measurement hysteresis is observed.

\subsubsection{Data collection}

After calibration is complete, a test temperature is selected and the heater turned on. Immediately as the graphite reaches the target temperature, a sample is lowered onto the graphite. The input voltage is modulated using the 6 volt power supply to ensure that the sled does not drive the sample into the heater and skew the regression results. Position measurements from the linear potentiometer are gathered to measure regression, while the thermocouples record the instantaneous temperature of both the heater and the graphite. The sample remains on the heater for $10-15$ seconds, then raised. This ends the data collection. Trials are conducted with new ABS samples in increments of $50^{\circ} \mathrm{C}$. After testing is complete, the data recorded by the computer are processed to to find the pyrolysis numbers. Figure 3.14 shows the LabVIEW program used to display and record the position and temperature data. 


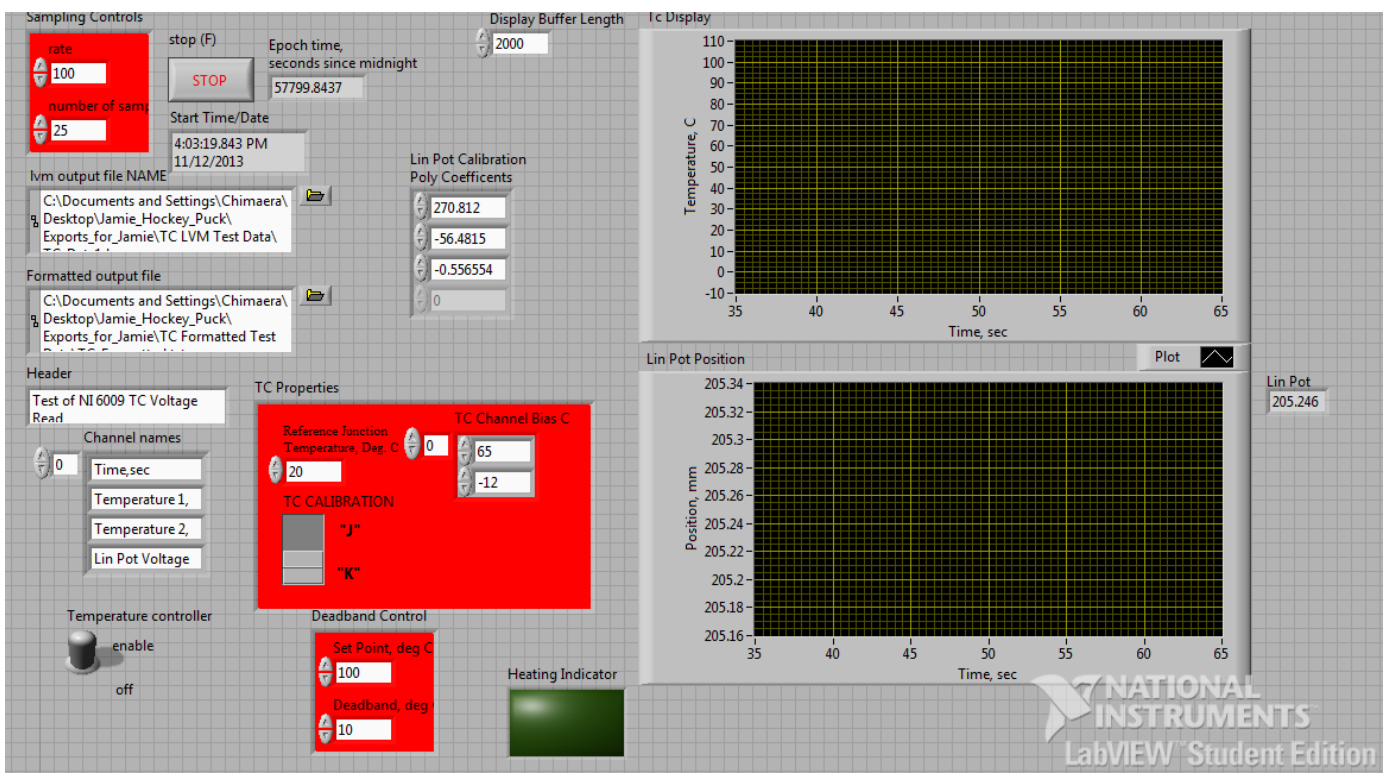

Fig. 3.14: LabVIEW program used for recording and displaying test temperatures and regression. 


\section{Chapter 4}

\section{Results}

\subsection{HTPB Results}

Twelve HTPB samples were tested on the test apparatus over a temperature range from $350^{\circ} \mathrm{C}$ to $600^{\circ} \mathrm{C}(423-873 \mathrm{~K})$. The results of these tests are shown in Figure 4.1. Estimates for $E_{a}$ and $h_{v}$ are shown in Table 4.1 in Section 4.3. Finding the regression rate is the first step in determining $E_{a}$. The raw data are truncated to include only those times when the sample is in contact with the heater. These are the processed data. The processed data is then sorted into temperature and position arrays. A linear curve fit is applied to the position data, and the total regression is calculated from the maximum and minimum of that curve. This total regression is then divided by the mean of the temperature data to come up with an average regression rate. The regression rate is then plotted against the inverse of its mean temperature on a log-scale graph. This is the Arrhenius-type curve discussed in Section 3.1, Equation 3.2. Another linear curve fit is created for these points. The slope of this line, $\mu$, is the activation energy divided by the universal gas constant $R_{u}$. Equations 4.1-4.6 show the mathematical process taken to arrive at the activation energy.

$$
\begin{aligned}
\ln \dot{r} & =\ln A_{r e g}-\frac{E_{a}}{R_{u} T} \\
\ln \dot{r}-\ln A_{r e g} & =-\frac{E_{a}}{R_{u} T} \\
& =-\frac{E_{a}}{R_{u}} \frac{1}{T} \\
& =-\mu \frac{1}{T} \\
\Rightarrow \mu & =\frac{E_{a}}{R_{u}} \\
E_{a} & =\mu R_{u}
\end{aligned}
$$


A similar procedure is done for $h_{v}$ but instead of regression rate, the inverse of the total evaporation time, $\frac{1}{t_{\text {evap }}}$, is plotted against the inverse of the mean temperature. The total evaporation time is calculated by dividing the total length of the sample by its regression rate. This assumes that all the material is converted into gas by the heater, which is a reasonably good assumption. Little material was left on the heater after each test.

When compared with Chiaverini et al.'s data, both sets of data exhibit the same general trend. Activation energies are high for low temperatures, then decrease significantly after about $449^{\circ} \mathrm{C}(722 \mathrm{~K})$. This produces a "kink" in the Arrhenius-type curve fit, and is attributed to chemical processes such as depolymerization and cross-linking that dominate at lower temperatures [24]. This required two curve fits, one for the regression data taken above $450^{\circ} \mathrm{C}$ and one for the data taken below. Interestingly, Chiaverini et al. reported regression rates significantly greater than the ones recorded in these experiments. Also, the kink in this report's HTPB data occurred at a slightly higher temperature (735 K). Figure 4.2 displays a side-by-side comparison of Chiaverini et al.'s HTPB data and the data from this report's HTPB runs. By replicating this kink that Chiaverini et al. reported, the design and fidelity of the test stand used in this report is validated. The error bars represent the estimated error on the positional data gathered from the linear potentiometer and comes mostly from the observed noise on the thermocouples, as seen in Section 4.4. 


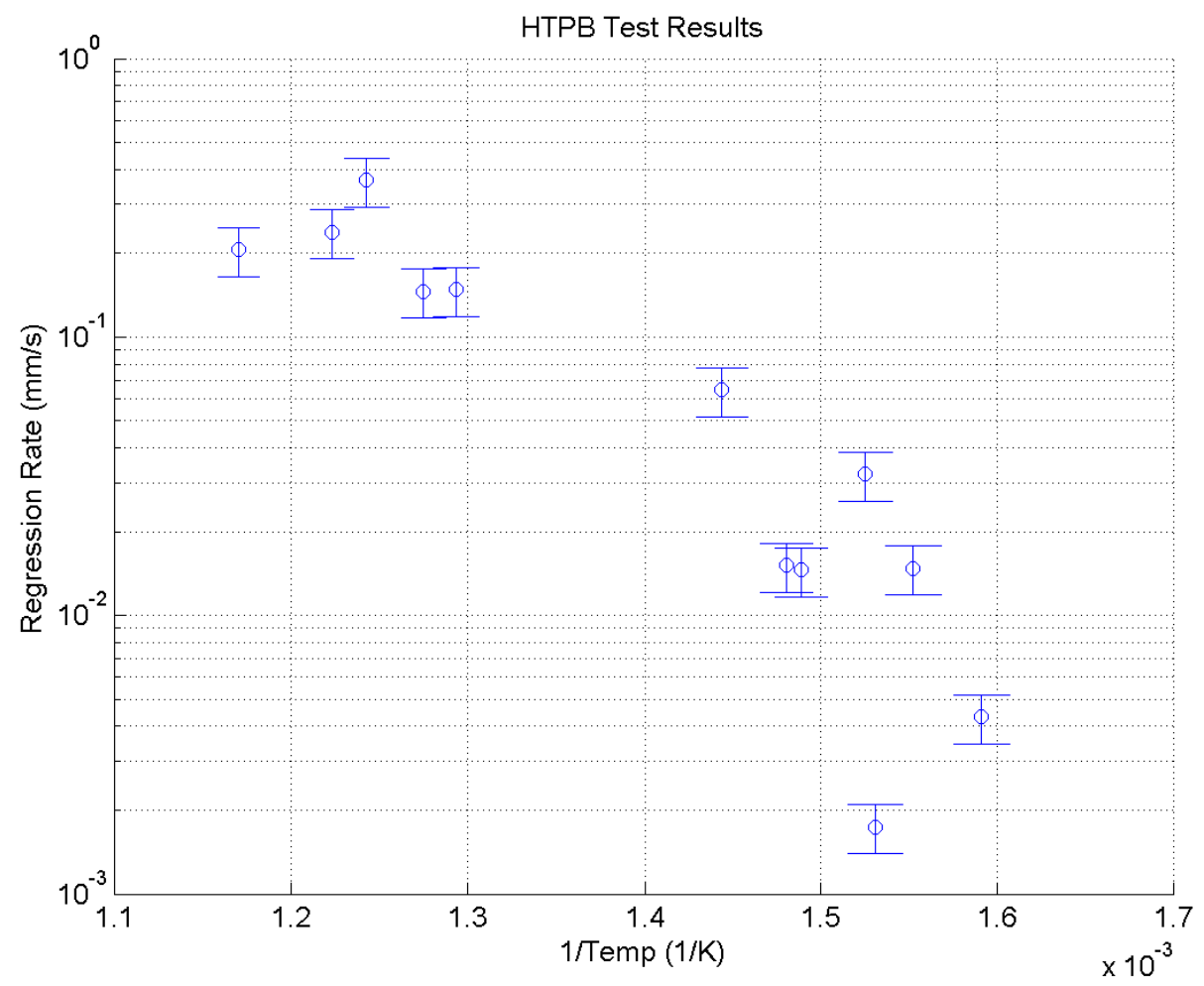

Fig. 4.1: Results of the HTPB tests, with error bounds. 


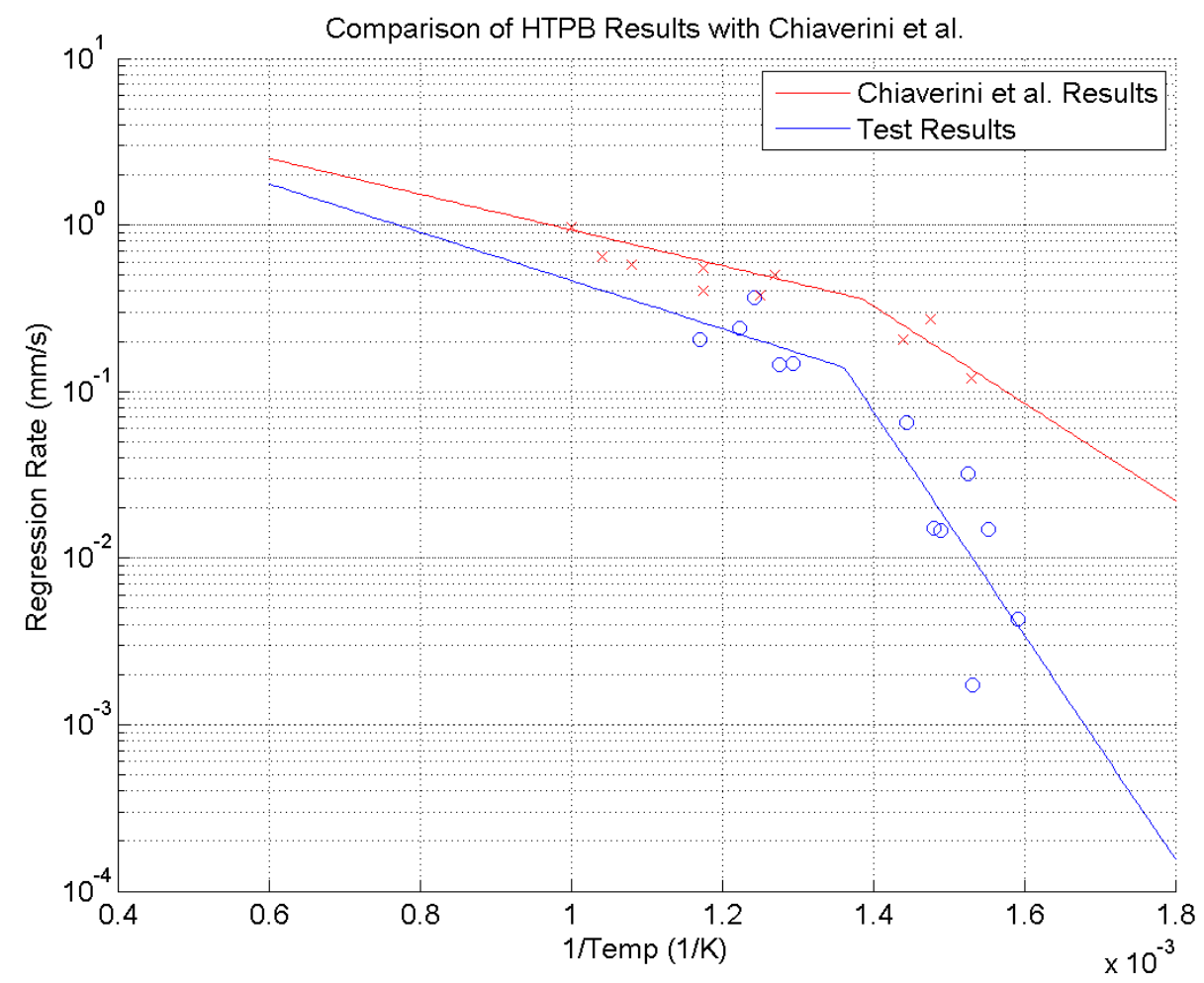

Fig. 4.2: Comparison of Chiaverini et al.'s HTPB data (red) vs. the HTPB data from this report (blue).

Pyrolysis data estimates are shown in Table 4.1 in comparison with the results from Chiaverini et al. The HTPB samples are assumed to have the same molecular weight, 2734 $\frac{\mathrm{kg}}{\mathrm{kg} \mathrm{mol}}$, as reported by Whitmore, Peterson, and Eilers [14]. No specific heat information is available for this HTPB blend; therefore, $h_{v}$ is reported instead of $h_{g}$.

\subsection{ABS Results}

Six tests of extruded ABS were conducted over a temperature range of $350^{\circ} \mathrm{C}$ to $650^{\circ} \mathrm{C}$. The same procedure outlined in Section 4.1 was used to find Figure 4.3 shows the results for extruded ABS. No chemical composition data are available on either type of ABS. Monomer ratios are highly variable and are closely-guarded; no molecular weight information was posted on the Stratasys website, nor were phone call queries answered. However, based on 
the data published by Cha and co-authors [9], a ratio of $20 \%$ acrylonitrile, $20 \%$ butadiene, and $60 \%$ styrene is assumed for the mass calculations. This gives a molecular weight of $83.92 \frac{\mathrm{kg}}{\mathrm{kg} \mathrm{mol}}$. Activation energy is estimated to be $31.07 \frac{\mathrm{kJ}}{\mathrm{mol}}\left(370.18 \frac{\mathrm{kJ}}{\mathrm{kg}}\right)$, while the heat of vaporization is estimated to be $0.061 \frac{\mathrm{kJ}}{\mathrm{mol}}\left(0.72 \frac{\mathrm{kJ}}{\mathrm{kg}}\right)$. Heat of gasification, calculated using Peydró Rasero et al.'s specific heat estimate of $2.714 \frac{\mathrm{kJ}}{\mathrm{kgK}}$, is $231.4 \frac{\mathrm{kJ}}{\mathrm{kg}}$. The activation energies are significantly better than the HTPB values on the molecular level, but are worse on a per-mass basis. This indicates that extruded ABS may be a better fuel than HTPB if a more optimal monomer ratio for ABS is used. Heat of vaporization was significantly better over the temperature range at which combustion occurs. Also, extruded ABS regression data are fairly linear over the test range and exhibits no "kink" in the trendline. This implies that the combustion process for ABS may be simpler and more efficient than HTPB. Finally, regression rate was higher for the extruded ABS than HTPB, further demonstrating a possible superiority of ABS as a fuel over HTPB.

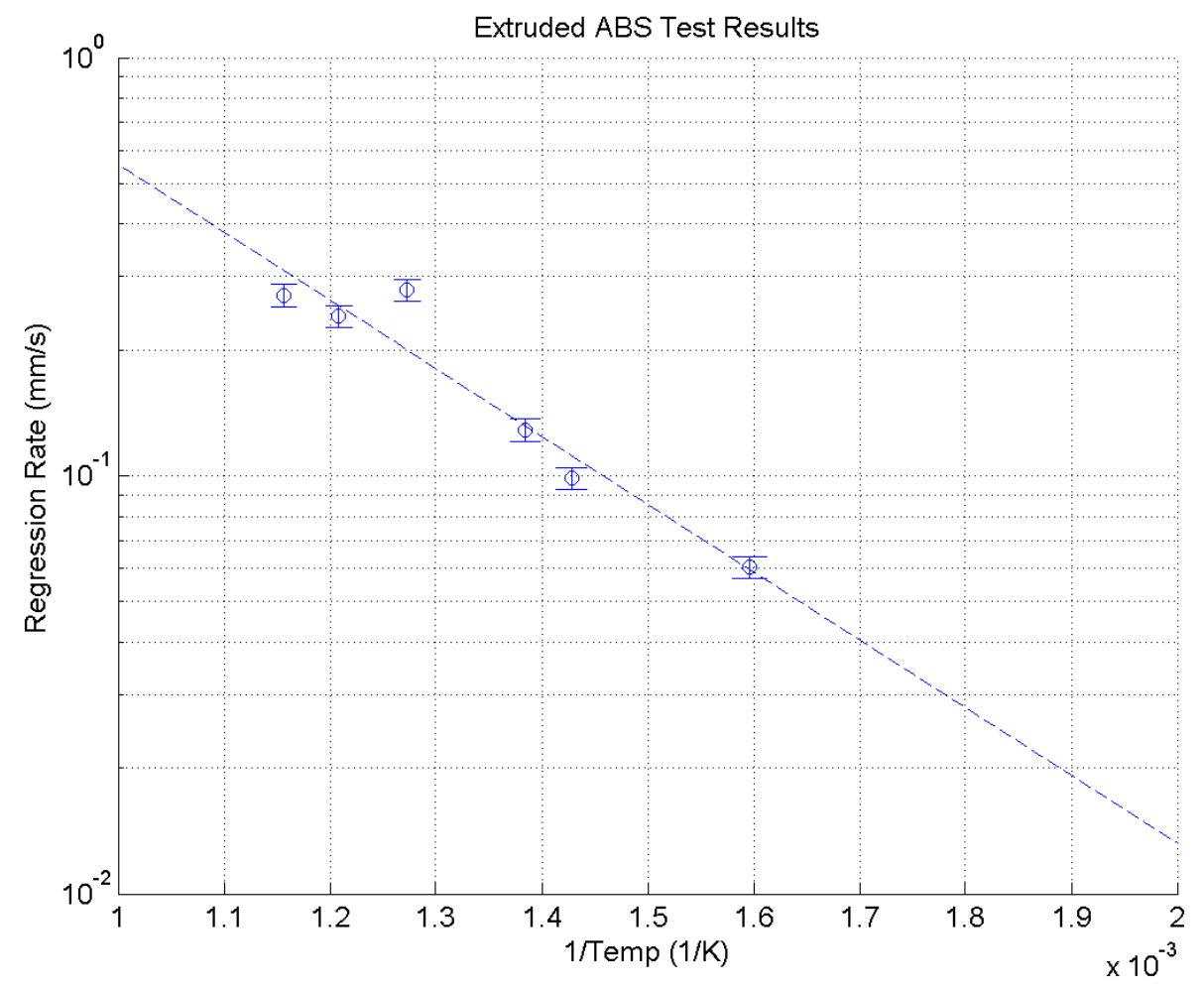

Fig. 4.3: Results of the extruded ABS tests, with error bounds. 
Five tests of rapid-prototyped ABS were conducted over the same temperature range as the extruded ABS, as seen in Figure 4.4. Activation energy is estimated to be $56.72 \frac{\mathrm{kJ}}{\mathrm{mol}}$ $\left(663.97 \frac{\mathrm{kJ}}{\mathrm{kg}}\right)$, while the heat of vaporization is estimated to be $1.02 \frac{\mathrm{kJ}}{\mathrm{mol}}\left(11.93 \frac{\mathrm{kJ}}{\mathrm{kg}}\right)$. The ratio of activation energy to heat of vaporization is about 55 , about a hundredth of the ratio for extruded ABS. This is most likely due to the increase in regression rate seen in the rapidprototyped ABS compared with the extruded ABS. The heat of gasification is calculated to be $242.62 \frac{\mathrm{kJ}}{\mathrm{kg}}$. Although higher than the extruded ABS, the rapid-prototyped ABS still demonstrated marked improvement over HTPB at the molecular level. Further tweaking of the monomer ratios may yield better per-mass values. Heat of vaporization was also much better than HTPB over the temperature ranges that combustion occurs. Rapid-prototyped ABS also has the highest regression rates of any of the materials tested. Similarly to extruded ABS, regression rate data is fairly linear, which indicates a much simpler pyrolysis process.

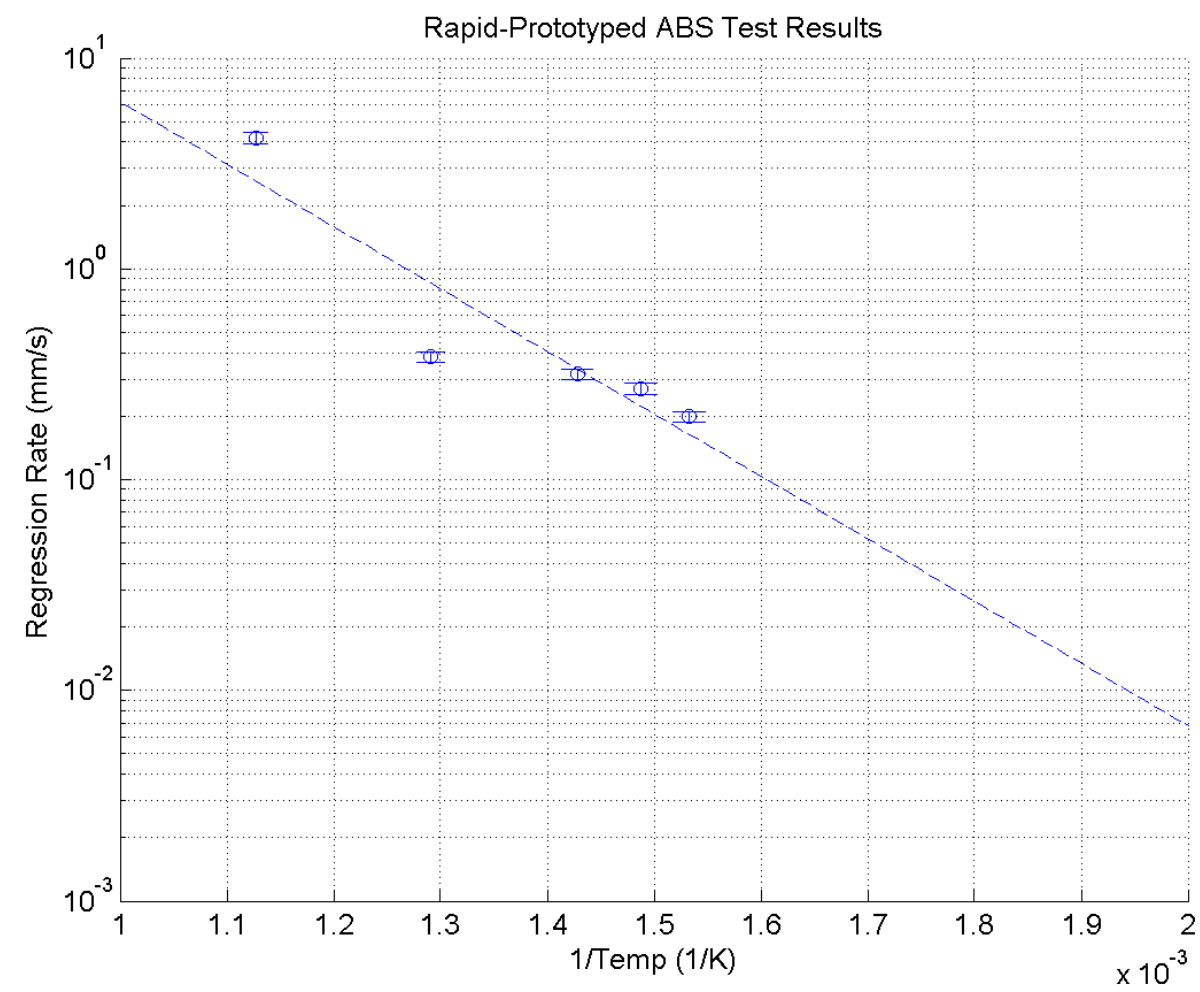

Fig. 4.4: Results of the rapid-prototyped extruded ABS tests, with error bounds. 


\subsection{Comparison Between HTPB and ABS Results}

Figure 4.5 shows the test results of the three materials overlaid on each other. Rapidprototyped ABS by far has the best regression rates. HTPB has the lowest heat of gasification, as well as activation energy on a per-mass basis, but its regression rates fare poorly at higher temperatures compared to the other two materials. Thus, given the same motor geometry, an HTPB motor would perform the best out of these materials. However, since ABS motors can be made with more complicated port shapes, rapid-prototyped ABS becomes an attractive option when designing a hybrid motor.

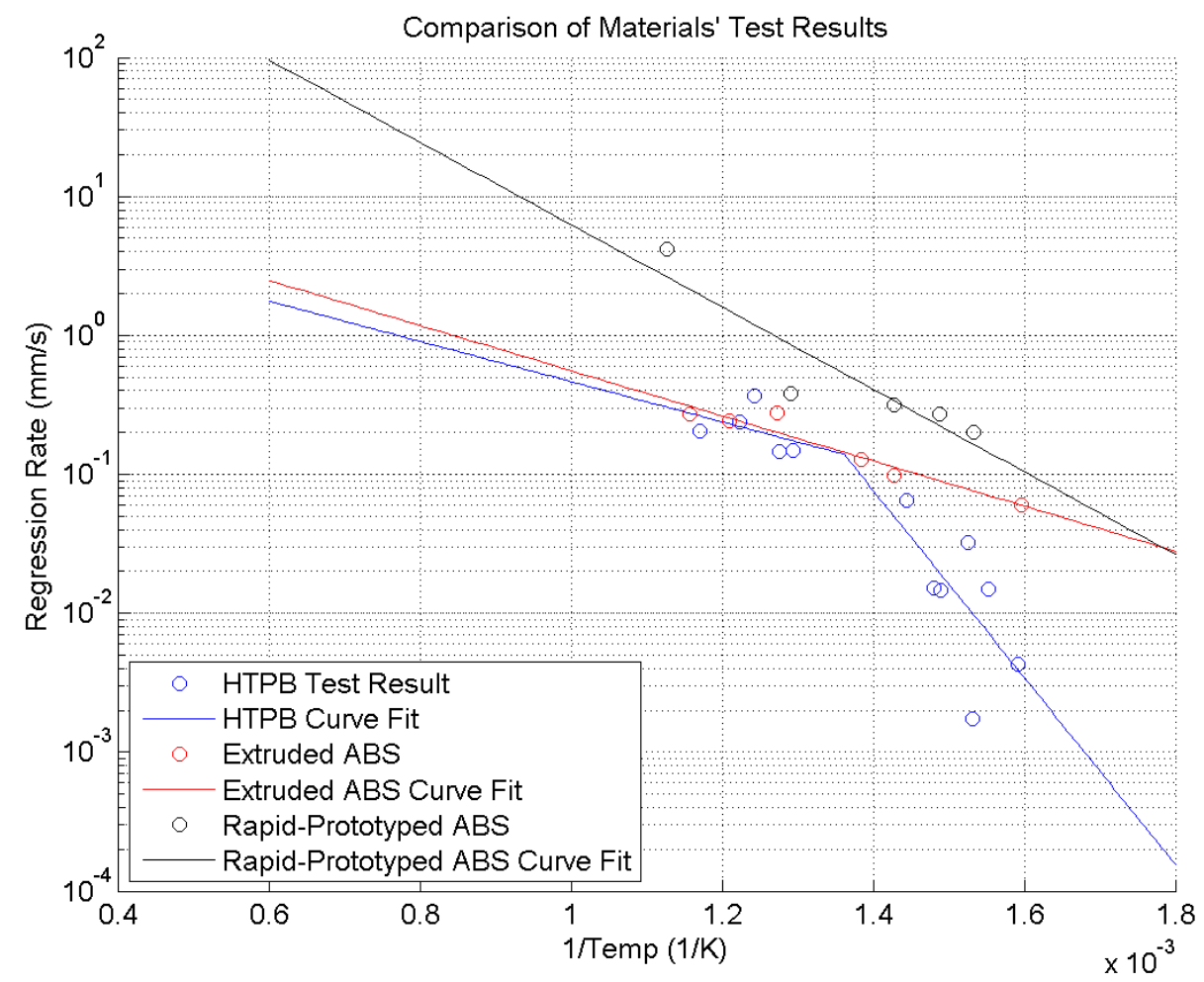

Fig. 4.5: Results from all three test materials: HTPB (blue), extruded ABS (red), and rapid-prototyped ABS (black). 
Table 4.1: Estimates for Activation Energy and Heat of Vaporization of HTPB.

\begin{tabular}{c|cc} 
& $E_{a}$ & $h_{v}$ \\
\hline HTPB, < $>22 \mathrm{~K}$, Chiaverini et al. [24] & $55.86 \frac{\mathrm{kJ}}{\mathrm{mol}}\left(23.46 \frac{\mathrm{kJ}}{\mathrm{kg}}\right)$ & $\mathrm{N} / \mathrm{A}$ \\
HTPB, > $722 \mathrm{~K}$, Chiaverini et al. [24] & $20.55 \frac{\mathrm{kJ}}{\mathrm{mol}}\left(9.87 \frac{\mathrm{kJ}}{\mathrm{kg}}\right)$ & $\mathrm{N} / \mathrm{A}$ \\
HTPB, <735 K & $128.8 \frac{\mathrm{kJ}}{\mathrm{mol}}\left(54.09 \frac{\mathrm{kJ}}{\mathrm{kg}}\right)$ & $0.029 \frac{\mathrm{kJ}}{\mathrm{mol}}\left(0.01 \frac{\mathrm{kJ}}{\mathrm{kg}}\right)$ \\
HTPB, >735 K & $27.71 \frac{\mathrm{kJ}}{\mathrm{mol}}\left(11.64 \frac{\mathrm{kJ}}{\mathrm{kg}}\right)$ & $0.10 \frac{\mathrm{kJ}}{\mathrm{mol}}\left(0.04 \frac{\mathrm{kJ}}{\mathrm{kg}}\right)$ \\
ABS, extruded & $31.07 \frac{\mathrm{kJ}}{\mathrm{mol}}\left(370.18 \frac{\mathrm{kJ}}{\mathrm{kg}}\right)$ & $0.61 \frac{\mathrm{kJ}}{\mathrm{mol}}\left(0.72 \frac{\mathrm{kJ}}{\mathrm{kg}}\right)$ \\
ABS, rapid prototyped & $56.72 \frac{\mathrm{kJ}}{\mathrm{mol}}\left(663.97 \frac{\mathrm{kJ}}{\mathrm{kg}}\right)$ & $1.02 \frac{\mathrm{kJ}}{\mathrm{mol}}\left(11.93 \frac{\mathrm{kJ}}{\mathrm{kg}}\right)$
\end{tabular}

\subsection{Error Analysis}

The experimental design has two sources of error: temperature error from the thermocouples and positional error from the linear potentiometer. The type $\mathrm{K}$ thermocouples has a temperature error of about $10^{\circ} \mathrm{C}$, which is also calculated from the observed noise. Using a linear curve fit on the linear potentiometer reduced the effects of positional error on the final results. This time history is shown in Figure 4.6. For the temperature error, an average value of temperature was taken and used in the regression rate calculations. Temperature biases were zeroed out at the beginning of each test, ensuring that the only source of temperature error was in the noise on the thermocouples. 


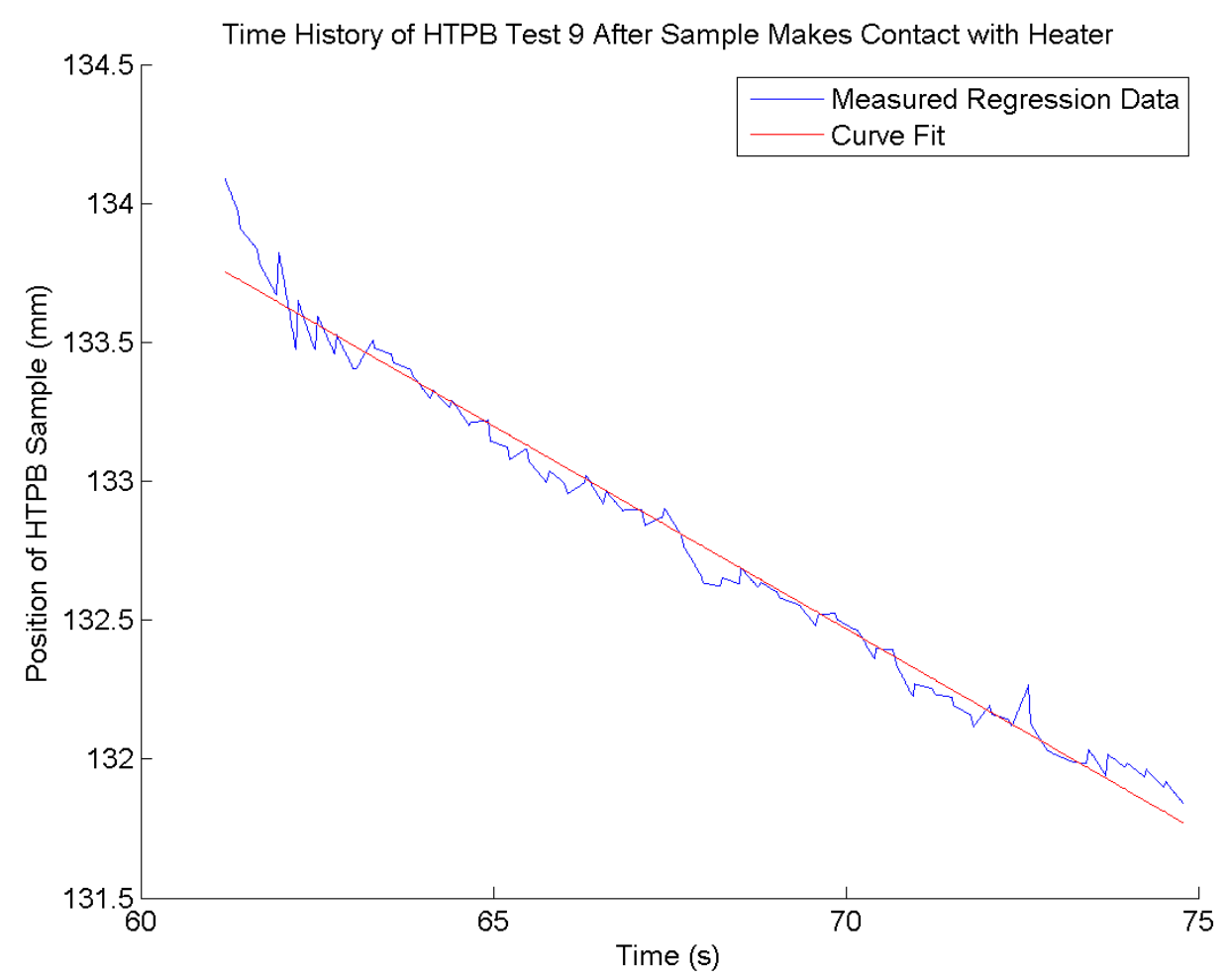

Fig. 4.6: Time history of an HTPB test run with the error-reducing fitted line.

Error calculations for the pyrolysis parameters are done as follows. After the fitted line is determined, the standard deviation of the data is computed. This is averaged over all the runs for a given material. For HTPB, the standard deviation is $0.0765 \frac{\mathrm{mm}}{\mathrm{s}}$, for extruded ABS it is $0.0402 \frac{\mathrm{mm}}{\mathrm{s}}$, and for rapid-prototyped ABS it is $0.0656 \frac{\mathrm{mm}}{\mathrm{s}}$. This is the standard deviation on the regression rate. These are multiplied by three to get a $95 \%$ confidence level. Additional error is associated with the activation energy, since there is uncertainty on both the regression rate and the temperature data. The error on the temperature, $10^{\circ} \mathrm{C}$, is inverted to get the inverse temperature error: $0.1^{\circ} \mathrm{C}$. However, to incorporate the regression 
rate uncertainty, Equation 4.7-4.9 must be applied first:

$$
\begin{aligned}
\Delta \dot{r} & =\Delta A-\exp \left(\frac{\Delta E_{a}}{\Delta T}\right) \\
\ln \Delta \dot{r} & =\frac{\Delta E_{a}}{\Delta T} \\
\Delta E_{a} & =\Delta T \ln \Delta \dot{r} .
\end{aligned}
$$

This gives a standard deviation of $0.257 \frac{\mathrm{kJ}}{\mathrm{kg} \cdot \mathrm{mol}}$ for HTPB, $0.321 \frac{\mathrm{kJ}}{\mathrm{kg} \cdot \mathrm{mol}}$ for extruded ABS, and $0.272 \frac{\mathrm{kJ}}{\mathrm{kg} \cdot \mathrm{mol}}$ for rapid-prototyped ABS. These are again multiplied by three to get the $95 \%$ uncertainty bound. Heat of vaporization has errors has the same error as the activation energy, plus an uncertainty on the length measurement of $0.1 \mathrm{~mm}$. When this error is taken into account, is is small compared to the other errors; therefore, it is ignored and the activation energy and heat of vaporization are assumed to have the same error. For the ABS, there is also error associated with the $c_{p}$ value. Peydró Rasero et al. did not record their uncertainty, so the error is assumed to be same as the activation energy error. Thus, the error on $h_{g}$ is assumed to be twice the error of $h_{v}$. Table 4.2 shows the error bounds for each material and its pyrolysis parameters.

Table 4.2: Uncertainty Bounds on the Regression Rate, Activation Energy and Heat of Vaporization for HTPB and ABS at 95\% Confidence Level.

\begin{tabular}{c|cccc} 
& $\dot{r}\left(\frac{\mathrm{mm}}{\mathrm{s}}\right)$ & $E_{a}\left(\frac{\mathrm{kJ}}{\mathrm{kg} \cdot \mathrm{mol}}\right)$ & $h_{v}\left(\frac{\mathrm{kJ}}{\mathrm{kg} \cdot \mathrm{mol}}\right)$ & $h_{g}\left(\frac{\mathrm{kJ}}{\mathrm{kg} \cdot \mathrm{mol}}\right)$ \\
\hline HTPB & \pm 0.230 & \pm 0.771 & \pm 0.771 & $\mathrm{~N} / \mathrm{A}$ \\
Extruded ABS & \pm 0.121 & \pm 0.963 & \pm 0.963 & \pm 2.89 \\
Rapid-prototyped ABS & \pm 0.197 & \pm 0.817 & \pm 0.817 & \pm 2.45
\end{tabular}




\section{Chapter 5 \\ Future Work}

\subsection{Heat Flux Measurements}

An area of future research is how much heat flux the ABS experiences during the combustion process. Understanding how the heat flux penetrates the ABS will allow for creation of better energy models for ABS hybrid motors, thus improving motor performance predictions. The calculation of heat flux should be relatively straightforward. Since the ABS sample would be heated in still air with little radiative heating, conduction will be the primary heating regime. Fourier's Law describes the heat flux in this regime:

$$
\vec{q}^{\prime \prime}=-k \nabla T(\rho, \theta, z)
$$

where $\vec{q}^{\prime \prime}$ is the heat flux vector, $k$ is thermal conductivity, and $T(\rho, \theta, z)$ is a scalar temperature field in cylindrical coordinates [76]. Assuming the graphite will be thoroughly insulated, heat flow will be initially modeled as one-dimensional, thus allowing the use of Equation 5.2

$$
q_{x}^{\prime \prime}=-k \frac{d T}{d x}
$$

In addition to perfect insulation, Equation 5.2 also assumes steady-state conditions. More comprehensive mathematical treatments are available for the transient case (such as Goldenberg's [80] three-dimensional transient heat conduction analysis), but since the graphite will be allowed to reach steady-state heating conditions, Equations 5.1 and 5.2 will be sufficient for present purposes.

Unfortunately, the biggest challenges in calculating heat flux will not be mathematical but mechanical. Insulating the graphite heater well enough for Equation 5.2 to be applicable is problematic. Most insulation rated for the temperatures of combustion is rigid and 
designed for linings of blast furnaces and kilns. Insulation made from aluminum oxide and silica fibers is flexible, but many layers would be required, making it too thick to be practical. A vacuum flask, or thermos, could be used to insulate the heater. Two stainless steel shells are formed and brazed together while still hot, trapping a layer of air between the shells. Then, evacuate the air, creating a vacuum between the layers of the device. This setup is more efficient at limiting heat flow through the sides of the graphite. However, the materials used in typical vacuum flask construction cannot withstand the temperatures the graphite is subjected to. More research will be needed to select a better insulation scheme before heat flux calculations can be carried out.

\subsection{Improvements to Thermocouple Mounting}

Thermocouple mounting issues were the biggest impediment to the research. Since the thermocouple needed to be imbedded into the graphite just below the ABS-graphite interface, a hole was drilled into the side of the graphite mass, just above the heater coil. Unfortunately, the hole was slightly too large, and the thermocouple would occasionally slip out and start reading either the heater coil or the ambient air temperature. Several tests were aborted because of this problem. In the future, a better way of mounting the thermocouple needs to be devised.

\subsection{Determining ABS Monomer Ratio}

One of the greatest hindrances to the characterization of ABS as a hybrid rocket fuel are the lack of molecular weight values. Without knowing whether a certain kind of ABS has more of one monomer, such as styrene, than another, determining the optimal monomer ratios for hybrid motor operation becomes very difficult. Comparisons between ABS would be limited to comparing different companies' ABS samples, giving no quantitative information on which $\mathrm{ABS}$ to use. If $\mathrm{ABS}$ can be tested with a known monomer ratio, optimal monomer ratios can be determined, allowing for better material selection when designing a hybrid rocket motor. 


\section{Chapter 6}

\section{Conclusion}

Acrylonitrile-butadiene-styrene (ABS) is common thermoplastic with excellent thermal and mechanical properties that make it a potentially good fuel for hybrid rocket propulsion systems. In addition, ABS is the material of choice for the additive manufacturing technique known as fused-deposition modeling (FDM) or paid prototyping. FDM has the potential to revolutionize the way hybrid rocket motors are made, due to its ability to print an infinite number of grain shapes and port geometries. Unfortunately, very little solid pyrolysis data, such as the activation energy $E_{a}$ and the heat of gasification $h_{g}$, are available for

ABS, especially over the temperature ranges and heat flux levels commonly experienced by operational hybrid rocket motors. Therefore, new experimentation is needed to determine these values.

Research on the activation energy of hydroxyl-terminated polybutadiene (HTPB) conducted by Chiaverini et al. used an innovative test stand to pyrolisize samples of HTPB and record the regression rate [24]. The regression rate data were then plotted against the inverse of the test temperature to generate a logarithmic curve analogous to Arrhenius curves. A line is then fit to the data. The slope of this line yields the activation energy. A similar procedure can be used to plot the inverse of time of total evaporation against the inverse of temperature to come up with the heat of vaporization, a key component of the heat of gasification. Simple modifications to Chiaverini et al.'s test design, most notably the addition of a linear potentiometer to record regression rates in situ, allow for the generation of these parameters for ABS.

Using a test stand based off Chiaverini et al.'s work, pyrolysis experiments were conducted on HTPB and extruded and rapid-prototyped ABS. The HTPB results compared favorably with those reported by Chiaverini et al. Although Chiaverini et al.'s regression 
rates were higher, probably due to differences in HTPB formulation, both Chiaverini et al. and this report came up with similarly-shaped Arrhenius-type curves. Both sets of HTPB data indicated that HTPB has two sets of activation energies, one for low temperatures and one for high temperatures. In Chiaverini et al.'s paper, the boundary between low and high temperatures for HTPB was found to be $722 \mathrm{~K}$ [24], while in this report, the boundary is at $735 \mathrm{~K}$. Activation energy in this report is calculated to be $111.03 \frac{\mathrm{kJ}}{\mathrm{mol}}\left(46.63 \frac{\mathrm{kJ}}{\mathrm{kg}}\right)$ before the "kink" in the Arrhenius-type curve and $27.71 \frac{\mathrm{kJ}}{\mathrm{mol}}\left(11.64 \frac{\mathrm{kJ}}{\mathrm{kg}}\right)$ after. Both values are slightly higher than the values reported in Chiaverini et al. These discrepancies can be explained one of two ways: either the HTPB formulation used in this report does not burn as readily as the Chiaverini et al. formulation, or that the camera method used to measure regression rate in Chiaverini et al.'s paper over-estimated the total regression. More HTPB tests of varying compositions may be required to further refine these values and close the gap with the data in Chiaverini et al.

Extruded ABS was observed to have greater regression rates than HTPB, especially in the low temperature regime. On a per-mole basis, the calculated activation energy of $31.07 \frac{\mathrm{kJ}}{\mathrm{mol}}$ is much better than HTPB and comes in at the low end of the activation energy estimates discussed in Section 1.2.4.2. Using an assumed molecular weight of $83.92 \frac{\mathrm{kg}}{\mathrm{kg} \mathrm{mol}}$, the per-mass activation of extruded ABS is found to be $75 \frac{\mathrm{kJ}}{\mathrm{kg}}$, significantly higher than HTPB. This could mean that extruded ABS requires more energy to initiate combustion. Heat of gasification is calculated to be $231.4 \frac{\mathrm{kJ}}{\mathrm{kg}}$. This represents one of the first attempts in published literature to quantify the heat of gasification for ABS. However, more research is needed to quantify how much this value will vary with differing ABS monomer ratios.

Rapid-prototyped ABS has the best regression rates of all the materials tested. This is most likely due to the tiny pockets of air that are trapped between the roads of the sample as it is being printed. Activation energy is calculated to be $56.72 \frac{\mathrm{kJ}}{\mathrm{mol}}\left(663.97 \frac{\mathrm{kJ}}{\mathrm{kg}}\right)$, and the heat of gasification is $242.62 \frac{\mathrm{kJ}}{\mathrm{kg}}$, assuming the same molecular weight as the extruded ABS. The $E_{a}$ values are slightly worse than the extruded ABS and HTPB but are lower than the estimates found in Section 1.2.4.2. On a per-mass basis, rapid-prototyped ABS has the 
worst activation energy and heat of gasification of the materials tested. Still, as Figure 4.5 illustrates, rapid-prototyped ABS regression rates compares very favorably with HTPB regression rates over the temperature range hybrid rocket motors operate.

For simple port geometries, HTPB is the material to use. It has better activation energy on a per-mass basis and a proven track record of success. However, if more complicated port geometries are used, better performance may be seen with a FDM-manufactured ABS motor. Many more-complicated port shapes, such as helix, show large increases in regression rate with no penalty in chamber pressure or form factor $[2,30]$. In addition, rapid-prototyped ABS motors show more consistent burn profiles [14] are easier to manufacture. With further research, ABS may one day supplant HTPB as the material of choice for hybrid rocket motors. 


\section{References}

[1] Sutton, G. P. and Biblarz, O., Rocket Propulsion Elements, chap. 16, "Hybrid Propellant Rockets", John Wiley and Sons, Hoboken, N.J., 8th ed., 2010, pp. 594-621.

[2] Bath, A., Performance Characterization of Complex Fuel Port Geometries for Hybrid Rocket Fuel Grains, Master's thesis, Dept. of Mechanical and Aerospace Engineering, Utah State University, Logan, UT, 2012.

[3] Luda di Cortemiglia, M. P., Camino, G., Costa, L., Roma, P., and Rossi, A., "Mechanisms of Action and Pyrolysis of Brominated Fire Retardants in AcrylonitrileButadiene-Styrene Polymers," Journal of Analytical and Applied Pyrolysis, Vol. 11, October 1987, pp. 511-526.

[4] Owen, S. R. and Harper, J. F., "Mechanical, Microscopical and Fire Retardant Studies of ABS Polymers," Polymer Degradation and Stability, Vol. 64, No. 3, June 1999, pp. 449455.

[5] Fink, J. F., Handbook of Engineering and Specialty Thermoplastics, Vol. 1, chap. 8, "Acrylonitrile-Butadiene-Styrene Polymers", Scrivener Publishing, Salem, MA, 2010, pp. $211-267$.

[6] Boresi, A. P. and Schmidt, R. J., Advanced Mechanics of Materials, John Wiley and Sons, 6th ed., 2003.

[7] Eilers, S. D., Whitmore, S. A., and Peterson, Z. W., "Regeneratively Cooled MultipleUse Plug Hybrid for Nanosatellites," Journal of Propulsion and Power, Vol. 29, No. 6, November 2013, pp. 1420-1434. 
[8] McCulley, J. M., Design and Testing of Digitally Manufactured Paraffin AcrylonitrileButadiene-Styrene Hybrid Rocket Motors, Master's thesis, Dept. of Mechanical and Aerospace Engineering, Utah State University, Logan, UT, 2012.

[9] Cha, J. and Co-authors, Engineering Plastics Handbook, chap. 6, "AcrylonitrileButadiene-Styrene (ABS) Resin", edited by J. M. Margolis, McGraw-Hill, 2006, pp. $101-130$.

[10] Rutkowski, J. V. and Levin, B. C., "Acrylonitrile-Butadiene-Styrene Copolymers (ABS): Pyrolysis and Combustion Products and their Toxicity-A Review of the Literature," Fire and Materials, Vol. 10, No. 3-4, March-April 1986, pp. 93-105.

[11] Kruth, J. P., "Material Incress Manufacturing by Rapid Prototyping Techniques," CIRP Annals - Manufacturing Technology, Vol. 40, No. 2, 1991, pp. 603-614.

[12] Yan, X. and Gu, P., "A Review of Rapid Prototyping Technologies and Systems," Computer-Aided Design, Vol. 28, No. 4, April 1995, pp. 307-318.

[13] Fuller, J., Ehrlich, D., Lu, P., Jansen, R., and Hoffman, J., "Advantages of Rapid Prototyping for Hybrid Rocket Motor Fuel Grain Fabrication," 47th AIAA/ASME/SAE/ASEE Joint Propulsion Conference and Exhibit, August 2011.

[14] Whitmore, S. A., Peterson, Z. W., and Eilers, S. D., "Analytical and Experimental Comparisons of HTPB and ABS as Hybrid Rocket Fuels," 47th AIAA/ASME/SAE/ASEE Joint Propulsion Conference and Exhibit, August 2011.

[15] Blom, H., Yeh, R., Wojnarowski, R., and Ling, M., "Detection of Degradation of ABS Materials via DSC," Journal of Thermal Analysis and Calorimetry, Vol. 83, No. 1, January 2006, pp. 113-115.

[16] Brown, T. L., LeMay, Jr., H. E., and Bursten, B. E., Chemistry: The Central Science, Pearson Education, Upper Saddle River, NJ, 10th ed., 2006. 
[17] Jun, H. C., Oh, S. C., Lee, H. P., Kim, H. T., and Yoo, K. O., "Pyrolysis Characteristics of Acrylonitrile-Butadiene-Styrene Resin," Journal of Industrial and Engineering Chemistry, Vol. 5, No. 2, June 1999, pp. 143-149.

[18] Wang, Y. and Zhang, J., "Thermal Stabilities of Drops of Burning Thermoplastics Under the UL 94 Vertical Test Conditions," Journal of Hazardous Materials, Vol. 246247, February 2013, pp. 103-109.

[19] Li, J. and Stoliarov, S., "Measurements of Kinetics and Thermodynamics of the Thermal Degradation for Non-charring Polymers," Combustion and Flame, Vol. 160, No. 7, July 2013, pp. 1287-1297.

[20] Baer, A. D., Hedges, J. H., Seader, J. D., Jayakar, K. M., and Wojcik, L. H., "Polymer Pyrolysis over a Wide Range of Heating Rates," AIAA Journal, Vol. 15, No. 10, October 1977, pp. 1398-1404.

[21] Bouck, L. S., Baer, A. D., and Ryan, N. W., "Pyrolysis and Oxidation of Polymers at High Heating Rates," Symposium (International) on Combustion, Vol. 14, No. 1, 1973, pp. $1165-1176$.

[22] van Krevelen, D. W. and Chermin, H. A. G., "Estimation of the Free Enthalpy (Gibbs Free Energy) of Formation of Organic Compounds from Group Contributions," Chemical Engineering Science, Vol. 1, No. 2, December 1951, pp. 66-80.

[23] Panagiotou, J., A Methodology for Flammability Diagrams, Master's thesis, Dept. of Fire Protection Engineering, University of Maryland, College Park, 2004.

[24] Chiaverini, M. J., Harting, G. C., Lu, Y. C., Kuo, K. K., Peretz, A., Jones, H. S., Wygle, B. S., and Arves, J. P., "Pyrolysis Behavior of Hybrid-Rocket Solid Fuels Under Rapid Heating Conditions," Journal of Propulsion and Power, Vol. 15, No. 6, NovemberDecember 1999, pp. 888-895.

[25] Kuo, K. K. and Chiaverini, M. J., Progress in Astronautics and Aeronautics, vol. 218: Fundamentals of Hybrid Rocket Combustion and Propulsion, chap. 15, "Challenges of 
Hybrid Rocket Propulsion in the 21st Century", edited by Martin J. Chiaverini and Kenneth K. Kuo, American Institute of Aeronautics and Astronautics, Reston, VA, 2007, pp. 593-638.

[26] Marxman, G. and Gilbert, M., "Turbulent Boundary Layer Combustion in the Hybrid Rocket," Symposium (International) on Combustion, Vol. 9, 1963, pp. 371-383.

[27] Altman, D. and Holzman, A., Progress in Astronautics and Aeronautics, vol. 218: Fundamentals of Hybrid Rocket Combustion and Propulsion, chap. 1, "Overview and History of Hybrid Rocket Propulsion", edited by Martin J. Chiaverini and Kenneth K. Kuo, American Institute of Aeronautics and Astronautics, Reston, VA, 2007, pp. 1-36.

[28] Karabeyoglu, M. A., Altman, D., and Cantwell, B. J., "Combustion of Liquefying Hybrid Propellants: Part 1, General Theory," Journal of Propulsion and Power, Vol. 18, No. 3, May-June 2002, pp. 610-620.

[29] Chiaverini, M. J., Progress in Astronautics and Aeronautics, vol. 218: Fundamentals of Hybrid Rocket Combustion and Propulsion, chap. 2, "Review of Solid-Fuel Regression Rate Behavior in Classical and Nonclassical Hybrid Rocket Motors", edited by Martin J. Chiaverini and Kenneth K. Kuo, American Institute of Aeronautics and Astronautics, Reston, VA, 2007, pp. 37-125.

[30] Chiaverini, M. J., Encyclopedia of Aerospace Engineering, vol. 2: Propulsion and Power, chap. 106, "Hybrid Propulsion", John Wiley and Sons, Chichester, West Sussex, UK, 2010, pp. 1201-1215.

[31] Marxman, G. A., Wooldridge, C. E., and Muzzy, R. J., Progress in Astronautics and Aeronautics, vol. 15: Heterogeneous Combustion, chap. 20, "Fundamentals of Hybrid Boundary-Layer Combustion", edited by Irvin Glassman and Hans G. Wolfhard, American Institute of Aeronautics and Astronautics, Reston, VA, 1964, pp. 485-522. 
[32] Williams, F. A., "Quasi-Steady Gas-Phase Flame Theory in Unsteady Burning of a Homogeneous Solid Propellant," AIAA Journal, Vol. 11, No. 9, September 1973, pp. $1328-$ 1330.

[33] Smoot, L. D. and Price, C. F., "Regression Rates of Nonmetalized Hybrid Fuel Systems," AIA A Journal, Vol. 3, No. 8, August 1965, pp. 1408-1413.

[34] Kosdon, F. J. and Williams, F. A., "Pressure Dependence of Nonmetalized Hybrid Fuel Regression Rates," AIAA Journal, Vol. 5, No. 4, April 1967, pp. 774-778.

[35] Eilers, S. D. and Whitmore, S. A., "Correlation of Hybrid Rocket Propellant Regression Measurements with Enthalpy-Balance Model Predictions," 43rd AIAA/ASME/SAE/ASEE Joint Propulsion Conference and Exhibit, July 2007.

[36] Houser, T. J., "Kinetics of Polymer Pyrolysis from Surface Regression Rates," Journal of Chemical Physics, Vol. 45, No. 3, August 1966, pp. 1031-1037.

[37] Lengellé, G., "Thermal Degradation Kinetics and Surface Pyrolysis of Vinyl Polymers," AIAA Journal, Vol. 8, No. 11, November 1970, pp. 1989-1996.

[38] Chiaverini, M. J., Serin, N., Johnson, D. K., Lu, Y. C., Kuo, K. K., and Risha, G. A., "Regression Rate Behavior of Hybrid Rocket Solid Fuels," Journal of Propulsion and Power, Vol. 16, No. 1, January-February 2000, pp. 125-132.

[39] Pastrone, D., "Approaches to Low Fuel Regression Rate in Hybrid Rocket Engines," International Journal of Aerospace Engineering, Vol. 2012, April 2012, pp. 125-132.

[40] Whitmore, S. A. and Chandler, S. N., "Engineering Model for Self-Pressurizing Saturated-N20-Propellant Feed Systems," Journal of Propulsion and Power, Vol. 26, No. 4, July 2010, pp. 706-714.

[41] Lengellé, G., Fourest, B., Godon, J. C., and Guin, C., "Condensed Phase Behavior and Ablation Rate of Fuels for Hybrid Propulsion," AIAA/ASME/SAE/ASEE 29th Joint Propulsion Conference and Exhibit, June 1993. 
[42] Voelcker, H. B. and Requicha, A. A. G., "Geometric Modeling of Mechanical Parts and Processes," Computer, Vol. 10, No. 12, December 1977, pp. 48-57.

[43] Kruth, J. P., Leu, M. C., and Nakagawa, T., "Progress in Additive Manufacturing and Rapid Prototyping," CIRP Annals - Manufacturing Technology, Vol. 47, No. 2, 1998, pp. $525-540$.

[44] Pham, D. T. and Gault, R. S., "A Comparison of Rapid Prototyping Technologies," International Journal of Machine Tool and Manufacture, Vol. 38, No. 10-11, October 1998, pp. $1257-1287$.

[45] Hinkley, D. A., "A Novel Cold Gas Propulsion System for Nanosatellites and Picosatellites," 22nd Annual AIAA/USU Conference on Small Satellites, 2008.

[46] Hoekstra, N. L., Kraft, B. P., and Newcomer, J. L., "Effect of Layer Orientation on the Mechanical Properties of Acrylonitrile-Butadiene-Styrene Test Specimens Produced by Fused Deposition Modeling," Journal of Injection Molding Technology, Vol. 5, No. 3, September 2001, pp. 193-199.

[47] Gascoin, N., Gillard, P., Mangeot, A., and Navarro-Rodrigues, A., "Detailed Kinetic Computations and Experiments for the Choice of a Fuel-Oxidiser Couple for Hybrid Propulsion," Journal of Analytical and Applied Pyrolysis, Vol. 94, March 2012, pp. 3340.

[48] Coats, A. W. and Redfern, J. P., "Thermogravimetric Analysis: A Review," Analyst, Vol. 88, No. 1053, 1963, pp. 906-924.

[49] Watson, E. S. and O’Neill, M. J., The Perkin-Elmer Corporation, Norwalk, CT, U.S. Patent for a "Differential Microcalorimeter", Patent No. 3,263,484, patented 2 August 1966.

[50] McAlevy III, R. F. and Hansel, J., "Linear Pyrolysis of Thermoplastics in Chemically Reactive Environments," AIAA Journal, Vol. 3, No. 2, February 1965, pp. 244-249. 
[51] Wilkie, C. A. and McKinney, M. A., Plastics Flammability Handbook: Principles, Regulations, Testing, and Approval, chap. 4, "Thermal Properties of Thermoplastics", edited by J. Troitzsch, Hanser, Munich, 3rd ed., 2004, pp. 58-76.

[52] Beck, W. H., "Pyrolysis Studies of Polymeric Materials Used as Binders in Composite Propellants: A Review," Combustion and Flame, Vol. 70, No. 2, 1987, pp. 171-190.

[53] McAlevy III, R. F. and Blazowski, W. S., "The Surface Pyrolysis Boundary Conditions for the Combustion of Polymers," The Mechanisms of Pyrolysis, Oxidation, and Burning of Organic Materials, 1972, pp. 185-192.

[54] Lyon, R. E. and Janssens, M. L., "Polymer Flammability," Final Report DOT/FAA/AR-05/14, Southwest Research Institute, sponsored by U.S. Department of Transportation and Federal Aviation Administration, 6220 Culebra Rd., P.O. Drawer 28510, San Antonio, TX 78228-0510, May 2005.

[55] Lengellé, G., Progress in Astronautics and Aeronautics, vol. 218: Fundamentals of Hybrid Rocket Combustion and Propulsion, chap. 3, "Solid-Fuel Pyrolysis Phenomena and Regression Rate, Part 1: Mechanisms", edited by Martin J. Chiaverini and Kenneth K. Kuo, American Institute of Aeronautics and Astronautics, Reston, VA, 2007, pp. $127-165$.

[56] Schultz, R. D. and Dekker, A. O., "The Absolute Thermal Decomposition Rates of Solids," Fifth Symposium (International) on Combustion, 1955, pp. 260-267.

[57] Barsh, M. K., Andersen, W. H., Bills, K. W., Moe, G., and Schultz, R. D., "Improved Instrument for the Measurement of Linear Pyrolysis Rates of Solids," The Review of Scientific Instruments, Vol. 29, No. 5, May 1958, pp. 392-395.

[58] Chaiken, R. F., Andersen, W. H., Barsh, M. K., Mishuck, E., Moe, G., and Schultz, R. D., "Kinetics of the Surface Degradation of Polymethylmethacrylate," Journal of Chemical Physics, Vol. 32, No. 1, January 1960, pp. 141-146. 
[59] McAlevy III, R. F., Lee, S. Y., and Smith, W. H., "Linear Pyrolysis of Polymethylmethacrylate During Combustion," AIAA Journal, Vol. 6, No. 6, June 1968, pp. 11371142.

[60] Nachbar, W. and Williams, F. A., "On the Analysis of Linear Pyrolysis Experiments," Ninth Symposium (International) on Combustion, August 1962, pp. 345-357.

[61] Cantrell, R. H., "Gas-Film Effects in the Linear Pyrolysis of Solids," AIAA Journal, Vol. 1, No. 7, July 1963, pp. 1544-1550.

[62] Cantrell, R. H., "Reply by Author to W. H. Andersen," AIAA Journal, Vol. 2, No. 2, February 1964, pp. 406-407.

[63] Andersen, W. H., "Comments on 'Gas-Film Effects in the Linear Pyrolysis of Solids'," AIAA Journal, Vol. 2, No. 2, February 1964, pp. 404-406.

[64] Levin, B., "A Summary of the NBS Literature Reviews on the Chemical Nature and Toxicity of the Pyrolysis and Combustion Products from Seven Plastics: AcrylonitrileButadiene-Styrenes (ABS), Nylons, Polyesters, Polyethylenes, Polystyrenes, Poly(Vinyl Chlorides), and Rigid Polyurethane Foams," Fire and Materials, Vol. 11, No. 3, September 1987, pp. $143-147$.

[65] Camino, G., Costa, L., and Luda di Cortemiglia, M. P., "Overview of Fire Retardant Mechanisms," Polymer Degradation and Stability, Vol. 33, No. 2, 1991, pp. 131-154.

[66] Suzuki, M. and Wilkie, C. A., "The Thermal Degradation of Acrylonitrile-ButadieneStyrene Terpolymer as Studied by TGA/FTIR," Polymer Degradation and Stability, Vol. 47, No. 2, 1995, pp. 217-221.

[67] Shapi, M. M., "TG and DSC Studies of Some Thermal Properties and Stability Aspects of Poly(Acrylonitrile Butadiene Styrene), Polystyrene, and Poly(Acrylonitrile Styrene) Plastics," Thermochimica Acta, Vol. 175, No. 1, February 1991, pp. 25-34.

[68] Luda di Cortemiglia, M. P., Camino, G., Costa, L., and Guaita, M., "Thermal Degradation of ABS," Thermochimica Acta, Vol. 93, September 1985, pp. 187-190. 
[69] Yang, M. H., "The Thermal Degradation of Acrylonitrile-Butadiene-Styrene Terpolymer Under Various Gas Conditions," Polymer Testing, Vol. 19, No. 1, February 2000, pp. $105-110$.

[70] Yen, H. Y., Lee, F. S., and Yang, M. H., "Thermal Degredation of Polysulfones. VI: Evaluation of Thermal Pyrolysis of Acrylonitrile-Butadiene-Styrene Terpolymer," Polymer Testing, Vol. 22, No. 1, February 2003, pp. 31-36.

[71] Marcilla, A. and García-Quesada, J. C., "Some Additional Considerations to the Paper Entitled: 'Thermal Degredation of Polysulfones. VI: Evaluation of Thermal Pyrolysis of Acrylonitrile-Butadiene-Styrene Terpolymer,", Polymer Testing, Vol. 26, No. 7, October 2007, pp. 960-967.

[72] Staggs, J. E. J., "The Heat of Gasification of Polymers," Fire Safety Journal, Vol. 39, No. 8, November 2004, pp. 711-720.

[73] Palmer, A., "Investigation into the Effect of Different Fuel Grain Materials on the Performance of a Hybrid Rocket Motor," Tech. rep., University of Hertfordshire, Hatfield, Hertfordshire, UK, 2007.

[74] Peydró Rasero, M. A., Juarez Varón, D., Boronat Vitoria, T., and Farrandiz Bou, S., "Determination of Specific Heat Capacity of a Thermoplastic Material (ABS) for Use in Computer Aided Simulation in the Injection Molding Process," Third Manufacturing Engineering Society International Conference, edited by V. J. Segui and M. J. Reig, Vol. 1181, 2009, pp. 743-747.

[75] Brennan, J. F., Shapiro, J. S., and Watton, E. C., "Evaporation of Liquids: A Kinetic Approach," Journal of Chemical Education, Vol. 51, No. 4, April 1974, pp. 276.

[76] Incropera, F. P., DeWitt, D. P., Bergman, T. L., and Lavine, A. S., Fundamentals of Heat and Mass Transfer, John Wiley and Sons, Hoboken, N.J., 6th ed., 2007.

[77] Noranzyk, A., "Thermal Conductivity Measurements of Graphite Samples," Journal of Young Investigators, December 2009, Online. 
[78] Picard, S., Burns, D. T., and Roger, P., "Measurement of the Specific Heat Capacity of Graphite," Tech. Rep. BIPM-2006/1, International Bureau of Weights and Measures, Pavillon de Breteuil, F-92312 Sèvres cedex France, January 2006.

[79] Null, M. R., Lozier, W. W., and Moore, A. W., "Thermal Diffusivity and Thermal Conductivity of Pyrolytic Graphite from 300 to 2700 K," Carbon, Vol. 11, No. 2, April 1973, pp. 81-87.

[80] Goldenberg, H., "Derivation of Three-Dimensional From Two-Dimensional Solutions of Transient Heat Conduction Problems," The Quarterly Journal of Mechanics and Applied Mathematics, Vol. 16, No. 4, November 1963, pp. 483-505. 